\title{
Long-term effects of environmental endocrine disruptors on reproductive physiology and behavior
}

\section{Heather B. Patisaul* and Heather B. Adewale}

Department of Biology, North Carolina State University, Raleigh, NC, USA

\section{Edited by:}

Larry J. Young, Emory University

School of Medicine, USA

Yerkes National Primate Research

Center, USA

\section{Reviewed by:}

John Vandenbergh, North Carolina State University, USA

Jason Richardson, Robert Wood

Johnson Medical School, USA

David Crews, University of Texas at

Austin, USA

\section{*Correspondence:}

Heather B. Patisaul, Department of Biology, North Carolina State

University, Campus Box 7617, Raleigh,

NC 27695, USA.

e-mail: heather_patisaul@ncsu.edu
It is well established that, over the course of development, hormones shape the vertebrate brain such that sex specific physiology and behaviors emerge. Much of this occurs in discrete developmental windows that span gestation through the prenatal period, although it is now becoming clear that at least some of this process continues through puberty. Perturbation of this developmental progression can permanently alter the capacity for reproductive success. Wildlife studies have revealed that exposure to endocrine disrupting compounds (EDCs), either naturally occurring or man made, can profoundly alter reproductive physiology and ultimately impact entire populations. Laboratory studies in rodents and other species have elucidated some of the mechanisms by which this occurs and strongly indicate that humans are also vulnerable to disruption. Use of hormonally active compounds in human medicine has also unfortunately revealed that the developing fetus can be exposed to and affected by endocrine disruptors, and that it might take decades for adverse effects to manifest. Research within the field of environmental endocrine disruption has also contributed to the general understanding of how early life experiences can alter reproductive physiology and behavior through non-genomic, epigenetic mechanisms such as DNA methylation and histone acetylation. These types of effects have the potential to impact future generations if the germ line is affected. This review provides an overview of how exposure to EDCs, particularly those that interfere with estrogen action, impacts reproductive physiology and behaviors in vertebrates.

Keywords: bisphenol, genistein, soy, estrogen receptors, development, sexual differentiation

\section{INTRODUCTION}

Growing awareness of the prevalence of environmental compounds, both synthetic and naturally occurring, with endocrine disrupting properties has generated considerable debate among scientists, regulatory agencies, and the general public about the potential longterm risks they pose for human and wildlife reproductive health. Is the endocrine disruption hypothesis plausible? Epidemiological evidence that human reproductive health is declining, particularly in Western nations, continues to mount. For example, sperm counts in Western countries appear to have declined by half in the past 50 years (Carlsen et al., 1992; Swan et al., 2000). In Demark, it is now estimated that more than $10 \%$ of men have sperm counts in the infertile range and up to $30 \%$ are in the subfertile range (Joensen et al., 2008). There are also indications that female fecundity is declining, even among young women, although the rate and degree to which this is occurring has been difficult to quantify (Brannian and Hansen, 2006; Frey and Patel, 2004; Nyboe Andersen and Erb, 2006). Within the United States, median age at menarche, first breast development, and sexual precocity has steadily advanced, especially among minority populations (Herman-Giddens et al., 1997; Partsch and Sippell, 2001). Similar trends have been noted in Europe and among children adopted from developing countries by Western parents (Aksglaede et al., 2009; Parent et al., 2003; Proos et al., 1991). The cause is likely complex and multi-faceted, but rapidity of the increase in reproductive and behavioral disorders suggests an environmental component. Whether or not endocrine disrupting compounds (EDCs) could be a contributing factor remains the subject of intense scrutiny and other determinants such as diet, stress, and body weight likely also play a role. At issue are both the degree to which low dose exposures to compounds with low hormonal potency can produce appreciable effects in the vertebrate reproductive system, and the difficulty of adequately assessing the potential long term risks of compounds with sex-, life stage-, and tissue-specific effects. Both issues are difficult to address experimentally because the timing, duration and level of human exposure are often uncertain. Moreover, the latency between EDC exposure and the emergence of consequential health effects can be considerably long, even decades, and the degree to which gene-environment interactions can produce inter-individual variability is poorly understood. Finally, predicting human responses from sentinel wildlife cases and from in vitro and animal tests of endocrine action is not straightforward. Nonetheless, there is reasonable and increasing evidence from in vitro and animal studies to suggest cause for concern. This review will address the potential long term physiological and behavioral effects of exposure to environmental endocrine disruptors in vertebrates, the evidence for human risk, and how this issue has transformed both endocrinology and toxicology.

An EDC is defined (in part) by the United States Environmental Protection Agency (EPA) as, "an exogenous chemical substance or mixture that alters the structure or function(s) of the endocrine system and causes adverse effects.... at the level of the organism, its progeny, and populations or subpopulations of organisms." This definition includes disruption of lactation, sexual maturation, the 
ability to produce viable, fertile offspring, sex specific behavior, and premature reproductive senescence. To date, the EPA has identified hundreds of compounds that fit this definition and thousands of others are suspected of having similar properties ${ }^{1}$ (Crisp et al., 1998; Toppari et al., 1996). Some of these compounds, such as oral contraceptives and a subset of pesticides, were specifically developed to target the endocrine system but the vast majority of chemicals on the EPA's list were neither designed nor intended to, especially in mammals. Some, such as DDT or the pyrethrins were developed to kill mosquitoes and other pests that spread serious and in some

${ }^{1}$ http://www.epa.gov/endocrine/Project.html cases life threatening human diseases such as malaria. Others were devised as flame retardants, to kill weeds, or to make plastics harder, clearer, and more resistant to heat stress (bisphenol-a) or more pliable (the phthalates). Compounds produced in nature rather than by humans, such as the phytoestrogens, also fit this definition (Figure 1).

\section{DDT: THE FIRST KNOWN ENDOCRINE DISRUPTOR}

The discovery that chemicals could interfere with the endocrine system in non-target species was first made by wildlife biologists who noted rapid population declines and abnormal reproductive physiology and behavior in multiple species. For example, as early as the

\begin{tabular}{|c|c|c|}
\hline Compound & Structure & Description \\
\hline Estradiol & & $\begin{array}{l}\text { Endogenous } \\
\text { Estrogen }\end{array}$ \\
\hline DDT & & Pesticide \\
\hline BPA & & $\begin{array}{l}\text { Plastics } \\
\text { Component }\end{array}$ \\
\hline GEN & & Phytoestrogen \\
\hline DBP & & Phthalate \\
\hline DEHP & & Phthalate \\
\hline
\end{tabular}

FIGURE 1 | Chemical structures and uses of common endocrine disruptors. DES, bisphenol-a and genistein are classified as estrogen agonists while both of the phthalates are androgen antagonists. DDT is classified as both an estrogen agonist and an androgen antagonist. 
1930s, famed Florida naturalist Charles Broley noticed abnormal courtship behavior, reduced nesting behavior, and diminishing birth rates among numerous bird species all across the United States and Canada, most notably bald eagles. His behavioral observations ultimately led him to hypothesize that heavy consumption of fish tainted with the widely used pesticide dichlorodiphenyltrichloroethane (DDT) was sterilizing the birds (Beans, 1996). This contention launched an unprecedented investigation by scientists who both doubted and embraced his hypothesis. It was ultimately determined that DDT and its metabolites, although they did not cause sterility (sperm counts in the birds were normal), feminized male embryos, weakened eggshells, and interfered with reproductive behavior to such a significant degree that it was decimating bird populations. These and similar cases were eloquently documented in the instant best selling book Silent Spring by Rachel Carsen (1962), the publication of which launched the modern environmental movement. She postulated that by liberally spraying pesticides in our zealous determination to destroy "pests," we were risking the systemic destruction of ourselves and our environment. This thesis fundamentally changed the public's perception of pesticide use and a decade later, DDT was ultimately banned in the United States largely as a result of public pressure.

The dramatic DDT story demonstrated that exposure to a compound not designed to interact with the endocrine system could induce profound reproductive deficits in non-target species. Despite this however, the capacity for DDT and its metabolites to impact human health is still widely disputed, particularly when exposure occurs at "low levels" rather than through an industrial accident or other large scale mechanisms. At high doses DDT is a potent neurotoxin, but numerous studies in laboratory animals, and in vitro assays have established that at low doses it can act as an endocrine disruptor. Even though DDT is no longer used in the US, human exposure to DDT and its metabolites is ongoing. For example, the primary metabolite of DDT, DDE, is far more persistent than the parent compound and thus still found in the environment at low levels. It is also highly lipophilic and accumulates in fat, so body burden increases with age. In addition, DDT is still used in many parts of the world, especially where the risk of contracting malaria, a disease which kills more people than cancer, heart disease or the HIV virus, is great. According the World Health Organization (WHO) nearly a million people died of malaria in $2006,91 \%$ of them children ${ }^{2}$. In contrast, no one is known to have died from routine DDT use. Whether or not DDT can induce disease or impair reproductive development in humans remains the subject of investigation and a controversial topic. A recent epidemiology study associated in utero or neonatal exposure with an increased risk of breast cancer (Cohn et al., 2007) a study which adds to a body of literature suggesting that prepubertal exposure to DDT may increase the risk of breast cancer (Clapp et al., 2008). Unfortunately many of the epidemiological studies exploring a potential association between DDT exposure and breast cancer risk have methodological weakness which make the data difficult to interpret, and many scientists remain skeptical that DDT exposure is a causative factor for breast cancer development (Beard, 2006). Emerging evidence from areas where DDT is still used suggests

${ }^{2}$ http://apps.who.int/malaria/wmr2008/malaria2008.pdf that DDT exposure might also be associated with other diseases including preterm birth, early pregnancy loss, reduced semen quality, disrupted menstruation, and problems with lactation (Beard, 2006; Rogan and Chen, 2005; Venners et al., 2005). But other factors, such as unreliable access to clean water and adequate nutrition are potential confounds and birth rates in these areas remain high. Nursing infants from these regions are frequently exposed to levels in breast milk which exceed the acceptable daily intake of $20 \mu \mathrm{g} / \mathrm{kg}$ body weight per day established by the WHO. Therefore the potential reproductive risk of DDT exposure is ongoing for many populations outside the US.

DDT, its metabolites, and the majority of other endocrine disruptors are now known to affect the endocrine system by multiple mechanisms, most notably by acting as weak estrogen agonists. Thus, the hypothesis that endocrine disruption is a significant health concern for humans would be strengthened by the demonstration that exposure to synthetic estrogens, particularly early in development, can have lasting effects. Unfortunately, this link has already been made.

\section{EVIDENCE OF THE POTENTIAL FOR ESTROGENIC ENDOCRINE DISRUPTORS TO AFFECT HUMAN HEALTH}

The clearest evidence that exposure to estrogen during fetal development can impact human reproductive health emerged from the widespread use of the potent synthetic estrogen diethylstilbestrol (DES, Figure 1). Beginning in 1938, DES was initially prescribed to prevent miscarriage but ultimately advertised and dispensed to pregnant women in general to produce "stronger babies" and even administered to newborns to enhance weight gain (Karnaky, 1953; Kuchera, 1971; Palmlund, 1996; Smith, 1948). It is estimated that DES was taken by four to six million (and possibly as many as 10 million) pregnant women in the US alone before human use was suspended in 1971 (Giusti et al., 1995). Non-medical use of DES was also common and thus a significant source of DES exposure, albeit in lower does. For example, it was frequently used in cosmetics, lotions, shampoo, and as a growth promoter in chicken and cattle. DES implants in poultry were outlawed in 1959 when DES residues were found in chicken liver, however this did not affect the use of DES in cattle, which remained ubiquitous until it was ultimately phased out in 1979. By the 1980s, more than $80 \%$ of US cattle were estimated to have been exposed, and considerable release of DES into the environment through feed lots and cattle waste has been well documented (Metzler, 1981; Zervos and Rodricks, 1982).

Unfortunately DES was ineffective at preventing miscarriage (Dodds et al., 1938) but the reproductive consequences to the developing offspring (both male and female) would ultimately prove to be extensive. One consequence of in utero DES exposure was first identified in 1971 by a group of keen eyed physicians who noticed that girls born to mothers who took DES during pregnancy (collectively referred to as "DES daughters") were more likely to develop an extremely rare type of cervicovaginal clear-cell adenocarcinoma (CCAC) (Herbst et al., 1970, 1971). One in 1000 DES daughters is now estimated to have developed CACC by the age of 34 (Giusti et al., 1995; Rubin, 2007) which is an extraordinarily high rate for such a rare form of cancer. DES exposure is also associated with increased incidences of vaginal dysplasia, vaginal 
and cervical adenosis and abnormalities of the cervix, vagina, and uterus. DES daughters suffer from reduced fertility, a higher risk of infertility, and more complicated and unsuccessful pregnancies. Complications include ectopic pregnancy, late spontaneous abortions and premature delivery (Palmlund, 1996; Palmlund et al., 1993). Increased rates of psychiatric disorders including depression, anorexia, phobias and learning disabilities have also been reported (Vessey et al., 1983). Damage from DES exposure is not limited to females. DES sons are also affected and show elevated rates of urogenital malformations, undescended testes, and testicular cancer. Low sperm density and mobility has also been observed (Gill et al., 1976; Palmer et al., 2005; Stenchever et al., 1981; Wilcox et al., 1995).

Most of the reproductive outcomes following fetal exposure to DES were predicted by or replicated in animal models (McLachlan et al., 1982; Newbold, 2008; Newbold and McLachlan, 1982). Thus, this unfortunate event in human medical history illustrates both the vulnerability of the developing fetus to estrogenic endocrine disruptors and the importance of animal models for predicting potential adverse effects in humans. Similarly, experimental work in multiple species was equally critical for establishing a causal link between DDT exposure and abnormal reproductive behavior accompanied by compromised fertility in wildlife populations (Beans, 1996; Guillette and Gunderson, 2001; Toppari et al., 1996). Therefore the importance of animal models in human risk assessment paradigms should not be underappreciated.

\section{KEY CONCEPTS OF ENDOCRINE DISRUPTION: TIMING, DOSE AND NONLINEAR EFFECTS}

The impact of the DES tragedy on the field of toxicology was transformative and three key principles of endocrine disruption emerged. First, the latency between fetal insult and the manifestation of physical or behavioral dysfunction can be extremely long, even decades. This concept had long been recognized by behavioral endocrinologists including Beach, Young, Goy and others exploring the mechanisms by which fetal hormone exposure could alter sexual behavior and sex specific neuroendocrine feedback systems (Balthazart et al., 1996; Gorski, 1963; Goy and Resko, 1972; Marler, 2005; Swaab and Hofman, 1984; Young et al., 1964), but was a breakthrough for toxicologists. It is now the basis for a conceptual framework termed the "fetal basis of adult disease," an idea that has transcended the endocrine disruption field. The concept that exposure to environmental factors, including toxicants, during fetal or neonatal life can interact with the genome and influence diseases which emerge years later including cancer, infertility, precocious puberty and obesity is potentially revolutionary and is currently a "hot topic" of research.

A second key concept of endocrine disruption is that the dose response of many hormones and EDCs appears to be nonmonotonic. This paradigm is anathema to the fundamental toxicological principle that "the dose makes the poison." The standard approach in toxicology, for experiments looking at acute exposure, is to expose either cells or animals to a few, generally high, concentrations of a given chemical. Selection of those doses is traditionally based on one of two standardized measurements called the $\mathrm{LD}_{50}$, which is the dosage lethal to $50 \%$ of the exposed organism or cells, and the lowest observed effect concentration (LOEC), which is the lowest concentration that produces readily observable morphological deformities. Similar designs using high (often near-lethal) doses that are not considered environmentally relevant are frequently used for subchronic and chronic exposure studies as well. These approaches assume that adverse effects increase proportionally and predictably with exposure level (generally linear or sigmoidal) and there is a threshold below which no effect is observed (termed the no observable adverse effect level or NOAEL). A level 1000-fold lower is then deemed the "safe" or "reference dose" for humans. With this model, potential low dose effects can be extrapolated from studies where doses in the range of the $\mathrm{LD}_{50}$ (or LOEC) are used. It also assumes that the observed effects will be obvious and include readily appreciable abnormalities. Unfortunately, there is growing evidence to suggest that the effects produced by hormones and many endocrine disruptors are not adequately predicted by this model because they have nonmonotonic dose responses that more closely approximate a U-shaped or inverted U-shaped curve (Andersen et al., 1999; Hayes et al., 2002; Sheehan, 2006; Vandenberg et al., 2006). In addition, effects, as seen with DES and CCAC, are likely to be more insidious and thus potentially difficult to readily identify. It is unclear how compounds can produce U-shaped dose effects but this response likely reflects an integration of two different mechanisms of action, each of which occurs at a different dose range (Vandenberg et al., 2009). Thus a compound like DDT could potentially interfere with estrogen (or androgen) action at low doses but act as a potent neurotoxin at levels closer to the $\mathrm{LD}_{50}$ (Toppari et al., 1996). It should be noted that although some toxicologists have expressed concern that nonmonotonic dose responses are underappreciated (Calabrese, 2001; Calabrese and Baldwin, 2003), others doubt their existence (Crump, 2001) and the concept remains highly contentious (Lutz et al., 2005; Melnick et al., 2002; Vandenberg et al., 2009).

A final principle of endocrine disruption made evident by the DES story is that the timing of exposure is crucial. The presence and extent of disorders common to DES sons and daughters varies substantially depending on the timing of the mother's first exposure, total dose, and length of exposure (Faber et al., 1990; Robboy et al., 1981, 1984). In humans and animals, there are critical windows of development, both for the reproductive organs and the brain, when sensitivity to hormones and EDCs is heightened. Again, this was not a novel concept to neuroendocrinologists but was previously underappreciated by toxicologists. Within this concept is also the recognition that the placenta is not impenetrable to EDCs and that, on the contrary, most EDCs likely reach the developing fetus. Maternal estrogens are effectively sequestered by $\alpha$-fetoprotein but most estrogen-like compounds only weakly or fail to bind to $\alpha$-fetoprotein and can therefore enter fetal circulation relatively unimpeded (Ikezuki et al., 2002; Milligan et al., 1998; Vandenberg et al., 2007). It is now widely accepted that development is a window of exceptional vulnerability to EDC exposure.

\section{ORGANIZATION OF REPRODUCTIVE NEUROENDOCRINE CIRCUITS}

During early development (gestation in humans, gestation and early neonatal life in rodents), the neuroendocrine feedback loops which regulate sex-specific reproductive physiology and behavior are sexually differentiated and organized. The coordination 
of physiological events and appropriate behavioral responses to them is paramount to reproductive fitness and the stability of a population. For example, the reproductive fitness of an ovulating female that fails to mate or nurse her young is just as diminished as the reproductive fitness of a female that fails to ovulate. Similarly, a male who responds to a soliciting female with aggression rather than courtship has a significantly decreased chance of passing along his genome even if he is physiologically capable of doing so. Thus, populations can be at risk when the integration of behavioral responses to physiological and environmental cues is disrupted. The organization of the neuroendocrine circuits that coordinate sex-specific physiology and behavior is orchestrated largely by steroid hormones, particularly estrogen, during distinct critical periods in embryonic and postnatal development (Cooke et al., 1998; Gorski, 1985; Simerly, 1998, 2002). The organization of these circuits appears to be particularly vulnerable to disruption by EDCs.

Maturation and function of the vertebrate reproductive system is coordinated by the hypothalamic-pituitary-gonadal (HPG) axis. This system encompasses a complex network of neuronal signaling pathways that enable the regulation of gonadotropin secretion by steroid hormones (Elkind-Hirsch et al., 1981; Gorski et al., 1975). The neural components of the HPG axis span multiple brain areas, primarily the hypothalamus, a diencephalic region important for coordination of many neuroendocrine functions including hunger, thirst, circadian cycles, emotion, body temperature and stress in addition to reproduction. It is responsive to a litany of external signals including day length, hormones, olfactory cues, and glucose levels, among others. Contained within the hypothalamus are discrete populations of neurons that regulate gonadotropin releasing hormone $(\mathrm{GnRH})$ secretion. The network of regulatory inputs from neuronal and glial cells in the brain projecting to these neurons is sexually differentiated by endogenous gonadal hormones (primarily estradiol in rodents but perhaps both estrogens and androgens in humans) through a series of gestational, pre- and perinatal critical periods (Cooke et al., 1998; Gorski, 1985; Simerly, 1998, 2002). In the post-pubertal animal, $\mathrm{GnRH}$ release is regulated through feedback effects of gonadal steroids. In both males and females, $\mathrm{GnRH}$ secretion is suppressed by steroid negative feedback, the signal for which is thought to arise from the arcuate nucleus (ARC) of the hypothalamus (Kauffman et al., 2007b; Tena-Sempere, 2006). In females, however, GnRH release is augmented once per cycle by estrogens. This positive feedback potentiates the surge in $\mathrm{GnRH}$ and, subsequently, luteinizing hormone (LH) that precedes ovulation (Clarke and Pompolo, 2005). This process is now thought to be mediated within the anterior hypothalamus (Adachi et al., 2007; Kauffman et al., 2007b; Tena-Sempere, 2006) and the sex specific organization of this system can be manipulated, inducing long term consequences. For example, it is well established that the administration of steroid hormones, including androgens or estrogens, during the neonatal critical period can masculinize the female rodent brain while castration can effectively prevent defeminization of the male rodent brain (Bakker and Baum, 2008; Baum, 1979; Simerly, 2002). Thus, in males castrated as neonates, the potential for estrogen to evoke a GnRH surge is preserved while, conversely, in females neonatally exposed to estrogens, this capacity is diminished or lost.
The neuroendocrine pathways regulating reproductive behavior are similarly organized and affected by steroid hormones. In rats, lordosis is a reflexive receptive posture made by the female in response to male mounting and is a hallmark indication of sexual receptivity. Whereas circulating estrogens play an essential role in stimulating lordosis in females (Davidson and Bloch, 1969; Lisk, 1969; Komisaruk and Diakow, 1973; Pfaff, 1999; Pfaff and Sakuma, 1979), males rarely display lordosis behavior even after estrogen administration in adulthood (Yamanouchi and Aria, 1976). However, neonatal steroid hormone manipulation can retain in the capacity to evoke lordosis in males, and suppress proceptive behavioral displays by females, indicating that sex-specific behaviors are also organized by steroid hormones in the perinatal period (Gerall, 1967; Gorski, 1963, 1985; Grady et al., 1965; Sodersten, 1978; Patisaul et al., 2009a; Whalen and Nadler, 1963; Whales et al., 1986). Thus, aberrant organization of sex specific neuroendocrine circuits can have profound and permanent effects on sex specific reproductive physiology and behavior. Consequently, the organization of neuroendocrine pathways is considered to be particularly vulnerable to endocrine disruption. Most examples detailed within this review result from endocrine disruption of the neuroendocrine system.

\section{LOW DOSE EFFECTS: HEALTH RISK OR HYPE?}

It is now evident that exposure to endocrine disruptors has the potential to adversely affect reproductive physiology and behavior in vertebrates. The critical question now is if wildlife and human health is at risk from chronic exposure to low doses of these compounds, either alone or in mixtures. DDT was applied liberally and has a long half life, thus affected wildlife populations had relatively high exposure levels. Moreover, DES has a binding affinity for ER $\alpha$ and $\operatorname{ER} \beta$ that is roughly equivalent to estradiol and is therefore a potent estrogen agonist (Korach et al., 1978; Sadler et al., 1998). Most endocrine disruptors exist at far lower levels in the environment and have binding affinities 100-10,000 times lower than either estradiol or DES. In some cases, however, blood levels of these compounds can be several fold higher than endogenous estrogen levels and suspected endocrine disruptors are almost always present in both the environment and in bodily fluids as mixtures. Although DDT and many other EDCs are classified as "weak estrogens" the precise mechanisms through which they interact with the vertebrate neuroendocrine system and the exposure levels that produce substantive effects are still largely undetermined. For example, DDT (and its metabolites) is now appreciated to act as both an estrogen agonist and an androgen antagonist highlighting the potential for compounds to have multiple mechanisms of action. Direct binding to steroid receptors is only one mode of action. Endocrine disruption also includes interference with the biosynthesis, transport, or metabolism of hormones or the disruption of the recruitment of binding proteins or transcription factors. Another key issue that remains poorly understood is how these compounds behave within mixtures. Wildlife and human populations are exposed to dozens if not hundreds of compounds simultaneously yet very little is known about how these compounds interact either in vitro or in vivo.

For simplicity, to address the question of whether or not endocrine disruptors have the potential to affect reproductive physiology and behavior at low doses, this review will focus on three compounds 
currently gaining wide scientific and public attention: genistein, bisphenol-a (BPA) and the phthalates. genistein and BPA are classified as weak estrogen agonists and thus presumably have similar mechanisms of action (Figure 1). However, genistein, because it is produced by plants and found in soy foods, is widely perceived as healthful while BPA, a component of polycarbonate plastics and epoxy resins, is commercially produced and was recently classified as a toxin in Canada (April, 2008). These attitudes are incongruous if the two compounds indeed elicit similar effects and therefore warrant further comparative investigation. The phthalates are found in a wide variety of products including cosmetics, pharmaceuticals, toys and medical devices. They are classified as androgen antagonists and their use was recently restricted in the US.

\section{GENISTEIN AND FEMALE REPRODUCTIVE PHYSIOLOGY}

The endocrine disrupting potential of phytoestrogens was first noticed in Australia in the 1940s when abnormally high rates of infertility, abortion, and reproductive abnormalities in newborn lambs were observed in ewes grazing on clover rich pastures (Bennetts and Underwood, 1951; Bennetts et al., 1946). It was ultimately determined that the steroid-like flavonoid phytoestrogens, most notably coumestrol, were responsible for the observed effects (Adams, 1995a,b; Braden et al., 1967). Decades later, a singular case of infertility and liver disease in captive cheetahs placed on a soy-based diet was ultimately attributed to the same class of compounds (Setchell et al., 1987). These incidents are reminiscent of the DDT story in wild bird populations, and have raised questions regarding the potential risk flavonoid phytoestrogens might pose to humans.

The two major classes of phytoestrogens are the lignans and the isoflavonoids. Lignans are minor components of cell walls and the highest concentrations are found in flaxseed (linseed) products, pumpkin seeds, green tea, coffee, and other fiber-rich foods (Axelson et al., 1982; Kuhnle et al., 2008; Mazur and Adlercreutz, 2000; Penalvo et al., 2008; Thompson et al., 1991, 2006). The isoflavonoids are most prevalent in legumes, especially soybeans and soy-based foods including soy infant formula, tofu and soy milk, but detectable levels also occur in fruits, vegetables, whole grains, and even some alcoholic beverages (Adlercreutz and Mazur, 1997; Fletcher, 2003; Franke et al., 1998a; Lapcik et al., 1998; Reinli and Block, 1996; Setchell et al., 1998). Dietary supplements containing high levels of isoflavonoid phytoestrogens are now widely available (Setchell et al., 2001). Of the many isoflavonoids found in soy, the most intensely scrutinized are genistein and daidzein.

Considerable attention is now being paid to the potential endocrine disrupting properties of isoflavonoids because soy consumption is widely promoted as being healthful and has been associated with reduced risk of cardiovascular disease and hormone dependent cancers (Adlercreutz and Mazur, 1997; Clarkson, 2002; Demonty et al., 2003; Peeters et al., 2003). In 1999, the US Food and Drug Administration (FDA) approved the health claim that daily consumption of $25 \mathrm{~g}$ of soy protein can reduce the risk of coronary artery disease (Food and Drug Administration, 1999). Soy consumption is increasing among all age groups, especially infants and children (Cao et al., 2009; Setchell, 2001; Strom et al., 2001). Genistein and other phytoestrogens readily cross the placenta indicating that fetal exposure is also potentially consequential (Todaka et al., 2005). Total isoflavone content in soy infant formula varies but is consistently high among soy foods, averaging near $40 \mu \mathrm{g}$ total isoflavones per gram of formula (Franke et al., 1998b; Johns et al., 2003; Setchell and Welsh, 1987; Setchell et al., 1997). This translates to a daily intake of approximately $6-9 \mathrm{mg} / \mathrm{kg}$ body weight per day, an amount, when adjusted for body weight, which is four to seven times higher than the amount consumed by adults on a traditional soy-based Asian diet or meeting the FDA guidelines (Barnes, 1995) and considerably higher than any synthetic EDC.

So is there cause for concern? The sheep and cheetah cases are disquietingly similar to the bird and other wildlife studies of the 1970s which ultimately identified the endocrine disrupting properties of DDT. But even today the question of whether or not DDT can impact human health is controversial, and such is the case with soy phytoestrogens. Is there any reasonably good evidence that phytoestrogens can have long term adverse health effects in humans following developmental exposure? A pair of studies on Puerto Rican girls associated neonatal phytoestrogen exposure with advanced pubertal onset, but a number of confounding factors including the use of potent estrogens in meat production, make the data problematic and difficult to interpret (Freni-Titulaer et al., 1986; Schoental, 1983). A more recent, retrospective cohort study found that young women fed soy-based infant formula as part of a controlled, University of Iowa feeding study reported longer menstrual bleeding and menstrual discomfort than those who were fed a non-soy based formula as babies (Strom et al., 2001). Beyond these epidemiology studies, very little is known about how exposure to soy phytoestrogens, either in the womb or in infancy, impacts female reproductive health or behavior in humans.

Data from animal research is more abundant. Neonatal exposure to genistein advances pubertal onset, increases the length of the estrous (menstrual) cycle and hastens the onset of persistent estrus in rodents. Female mice treated with $0.5-50 \mathrm{mg} / \mathrm{kg}$ genistein for only the first 5 days of life give birth to fewer live pups over time compared to untreated control animals, with fertility most strongly impacted at the highest dose (Jefferson et al., 2005). This acceleration of reproductive senescence could result from disruption anywhere within the HPG axis including the ovary and brain. Detailed work in mice by Jefferson and colleagues has revealed that genistein can interfere with ovarian differentiation resulting in ovarian malformations indicative of impaired fecundity such as multi-oocyte follicles, and attenuated oocyte cell death (Jefferson et al., 2002, 2006, 2007). Ovarian defects, including the absence of corpora lutea, the presence of large antral-like follicles with degenerating or no oocytes and numerous ovarian cysts have also been observed following neonatal genistein exposure in rats (Kouki et al., 2003) (Figure 2).

Recent studies in our laboratory have found that the organization of sexually differentiated neural pathways within the hypothalamus is also vulnerable to neonatal endocrine disruption by genistein. We determined that advanced vaginal opening and abnormal estrous cyclicity, induced by neonatal exposure to $10 \mathrm{mg} / \mathrm{kg}$ genistein, is accompanied by an impaired ability to stimulate $\mathrm{GnRH}$ neuronal activity (as measured by the immunoreactivity of both of GnRH and Fos) following ovariectomy and hormone priming (Bateman and Patisaul, 2008) (Figure 3). This observation indicates that neonatal genistein exposure has a masculinizing effect on the female HPG axis. Although GnRH neurons express ER $\beta$ 


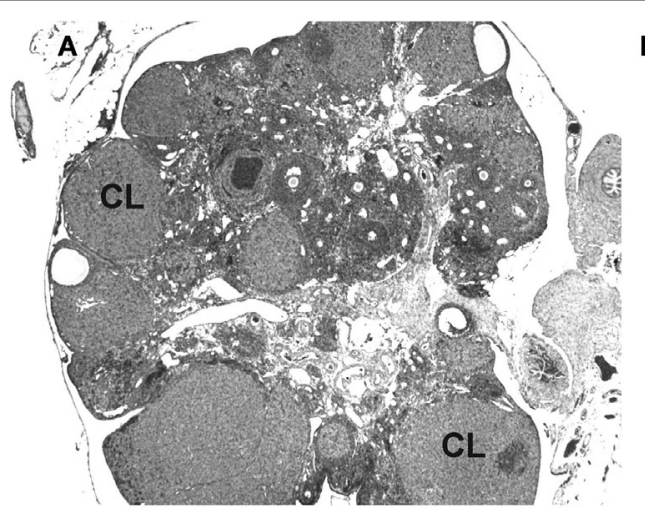

B

C
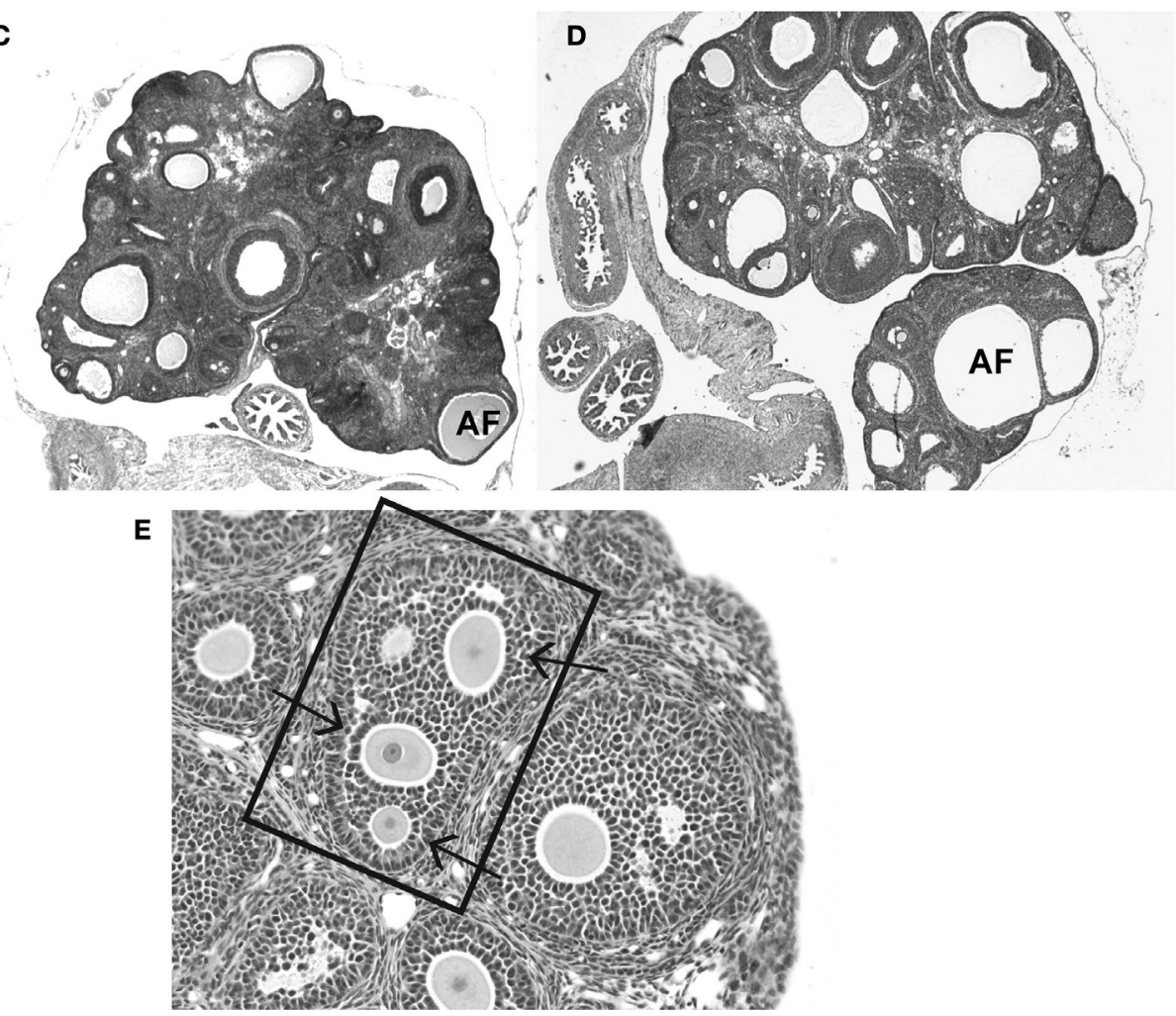

FIGURE 2 | Frequently observed ovarian malformations in rats following neonatal exposure to endocrine disruptors. (A) An ovary from an unexposed adult female contains follicles at all stages of folliculogenesis and numerous corpora lutea (CLs), indicative of successful ovulation. (B) Ovaries from females neonatally treated with the synthetic estrogen estradiol benzoate $(25 \mu \mathrm{g})$ show no signs of folliculogenesis, are undersized and lack CLs. The presence of numerous, large antral-like follicles (AF) most of which contain a degenerating or no oocyte and are frequently reminiscent of ovarian cysts, are commonly observed following neonatal exposure to (C) BPA (50 mg/kg bw) or (D) genistein (10 mg/kg bw). CLs are often absent or significantly reduced in number when numerous AFs are present. A multi-oocyte follicle (E) in a pre-pubertal ovary following neonatal treatment with estradiol benzoate $(10 \mu \mathrm{g})$. throughout development (Herbison and Pape, 2001; Hrabovszky et al., 2000, 2001) and thus could potentially respond to neonatal genistein directly, it is generally accepted that hormonal and other environmental signals are largely conveyed to GnRH neurons from other estrogen-responsive neurons clustered in different regions of the hypothalamus. In rodents, the two most significant regions appear to be the anterior ventral periventricular (AVPV) and arcuate (ARC) nuclei (Gu and Simerly, 1997; Polston et al., 2004; Polston and Simerly, 2006; Shughrue et al., 1997; Simerly et al., 1990) both of which contain sexually dimorphic populations of neurons that express the KiSS-1 gene. This gene codes for a family of peptides called kisspeptins (previously called metastins), and rapidly emerging evidence indicates that kisspeptin neurons are essential for coordinating pubertal onset and steroid feedback on GnRH neurons in many species, including humans (Kauffman et al., 2007a; Navarro et al., 2004; Smith et al., 2006a,b).AVPV kisspeptin neurons are more numerous in females than males and are thought to be essential for steroid positive feedback and the initiation of the preovulatory GnRH surge (Clarkson et al., 2008; Gottsch et al., 2004; Irwig et al., 2004; Kauffman et al., 2007a, Roa et al., 2006; 

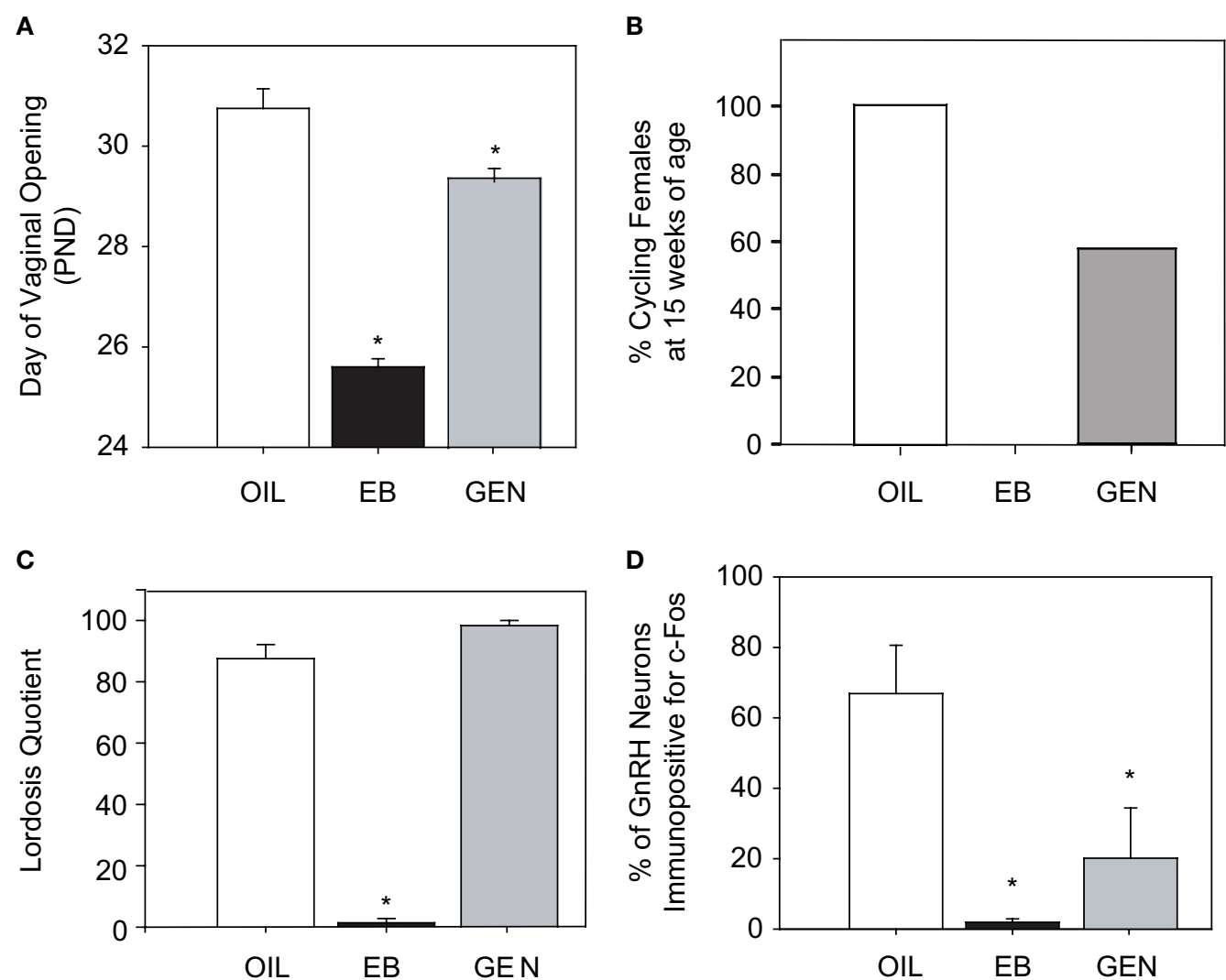

FIGURE 3 | Effects of neonatal exposure to genistein (GEN, $10 \mathrm{mg} / \mathrm{kg} \mathrm{bw}$ ) compared to an oil based vehicle (OIL), and estradiol benzoate (EB, $50 \mu \mathrm{g}$ ) on reproductive physiology and behavior in female rats. (A) GEN

significantly advanced the timing of pubertal onset as measured by day of vaginal opening compared to control females. (B) This corresponded with anovulation (by 15 weeks of age) in $43 \%$ of GEN females, compared to

none of the OIL females and all of the EB females. (C) There was no effect of GEN on sexual receptivity (following ovariectomy and hormone priming) however (D) the number of $\mathrm{GnRH}$ neurons also immunopositive for Fos was significantly reduced indicating an impaired capacity to display steroid positive feedback. (Panels (A) and (D) adapted from Bateman and Patisaul, 2008).

Smith et al., 2006b). In contrast, KiSS mRNA expression in the ARC is not thought to be sexually dimorphic and appears to be important for the regulation of steroid negative feedback (Kauffman et al., 2007a). We have now shown that neonatal exposure to $10 \mathrm{mg} / \mathrm{kg}$ genistein can significantly decrease the density of neuronal fibers immunolabeled for kisspeptin in the AVPV but not the ARC of female rats (Bateman and Patisaul, 2008; Patisaul et al., 2009b) indicating that disrupted organization of the kisspeptin signaling pathways may be a novel yet fundamental mechanism by which a suite of reproductive abnormalities are induced including disrupted timing of pubertal onset, irregular estrous cycles and premature anovulation.

Interestingly, animals exposed to genistein neonatally remained capable of displaying lordosis when ovariectomized, primed by the sequential administration of estradiol benzoate and progesterone, and paired with vigorous males (Figure 3). Lordosis behavior is also retained by female rats neonatally exposed to agonists selective for either ER $\alpha$ or ER $\beta$ but not estradiol benzoate suggesting that agonism of both ER subtypes may be needed to fully defeminize the behavior (Patchev et al., 2004; Patisaul et al., 2009a). It may also take a longer exposure or higher doses, a possibility which illustrates the important concepts of dose and timing when considering the potential effects of EDCs. Further complicating the issue is a report that selective agonism of ER $\beta$ results in a statistically significant reduction, but not elimination, of lordosis behavior in mice (Kudwa et al., 2006). This could be a species difference in sensitivity or the relative role ER $\beta$ plays in the organization of the neuroendocrine pathways that mediate the lordosis response. Further work will be needed to clarify this issue.

The mechanisms by which genistein and the other phytoestrogens influence sex-specific physiology are likely diverse. Genistein has a higher relative binding affinity for both $\mathrm{ER} \alpha$ and $\mathrm{ER} \beta$ in vitro than most other EDCs and a higher binding affinity for ER $\beta$ that for ER $\alpha$ (Kuiper et al., 1998). Genistein is also a potent inhibitor of tyrosine protein kinases (Boutin, 1994; Piontek et al., 1993), which catalyze phosphorylation of their own tyrosine residues and those of other proteins, including growth factors involved in tumor cell proliferation. In addition, genistein can also inhibit DNA topoisomerases I and II, enzymes essential for DNA replication (Kurzer and Xu, 1997; Okura et al., 1988) and may also work through epigenetic mechanisms involving both hyper and hypomethylation (Dolinoy et al., 2006; Tang et al., 2008). A further 
complication is the observation that effects of genistein administration at low doses are compounded when co-administered with other EDCs (Kurzer and Xu, 1997; You et al., 2002). Mixture effects of phytoestrogens, as with most other EDCs, are generally unappreciated.

\section{BISPHENOL-A (BPA): A DYNAMIC AND ONGOING CONTROVERSY}

BPA is somewhat unique among EDCs because, in the early twentieth century, it was being developed as a possible synthetic estrogen (a pursuit which was abandoned following the synthesis of DES) (Dodds and Lawson, 1936). Since the 1950s, it has been used primarily in the production of polycarbonate plastic products to improve clarity and increase resilience. It is also a component of epoxy resins used to line the interior of metal cans such as soda and soup cans. Human exposure to BPA occurs through everyday use of these items because it can migrate from the container into the contents, especially when heated (Brede et al., 2003). The United States Centers for Disease Control recently estimated that nearly all Americans have detectable levels of BPA in their bodies, with children having higher levels than adults (Calafat et al., 2005, 2008). Infants in neonatal intensive care units have particularly high exposure to BPA, presumably from its use in medical devices and from the migration of BPA into infant formula from the container (Calafat et al., 2009). In addition, newborns can be exposed through lactational transfer (Tsutsumi, 2005) and relatively high levels in umbilical cord blood and fetal serum (compared to maternal blood levels) indicate that BPA fails to bind $\alpha$-fetoprotein and can expose the developing fetus (Ikezuki et al., 2002; Vandenberg et al., 2007). Exposure to BPA is not limited to humans, and effects on wildlife from contaminated water supplies have been documented in both males and females of multiple species (Crain et al., 2007; Maffini et al., 2006; vom Saal et al., 2007).

Although it was once thought that BPA could function as a synthetic estrogen, BPA was not considered to pose a significant threat to either wildlife or human populations because its binding affinity for the primary forms of the estrogen receptor $(\mathrm{ER} \alpha$ and $E R \beta)$ is approximately 10,000-fold weaker than that of estradiol or DES (Gould et al., 1998; Kuiper et al., 1998). Yet, numerous studies from multiple laboratories have shown that BPA can impact reproductive physiology and behavior in rodents at doses even lower than the current reference or "safe" exposure limit for humans of $50 \mu \mathrm{g} / \mathrm{kg}$ body weight per day (Vandenberg et al., 2009). The mechanism(s) of low dose activity remains poorly understood but has long been hypothesized to be most potent in hormone sensitive organs and brain regions when endogenous estrogens are low or absent (vom Saal and Moyer, 1985). Thus, like DES, at different life stages BPA may have profoundly different effects on the same brain region or organ. It may also act through nonclassical estrogen pathways such as those mediated via membrane ERs, GPR30 or the newly discovered estrogen-related receptor $-\gamma($ ERR- $\gamma$ ) (Matsushima et al., 2007; Thomas and Dong, 2006; Watson et al., 2007).

Despite the controversy surrounding the mechanism by which low dose exposure to BPA could affect reproductive physiology, the evidence for widespread effects in animal models is increasing. Effects of perinatal exposure observed at the $50 \mu \mathrm{g} / \mathrm{kg}$ body weight dose or lower include advanced vaginal opening and the hastened onset of first estrus indicating advanced puberty (Adewale et al., (in press); Honma et al., 2002). Ovarian malformations including increased number of blood-filled ovarian bursae, indicative of advanced reproductive aging, abnormal numbers of antral follicles, aneuploidy and decreased corpora lutea (Figure 2) have also been observed by us and others (Adewale et al., (in press); Markey et al., 2003; Susiarjo et al., 2007). BPA can also induce apoptosis and cell arrest in cultured ovarian granulosa cells (Xu et al., 2002). Prolonged, irregular estrus cycles are also frequently observed by us and others following perinatal exposure to low doses suggesting compromised fertility (Adewale et al., (in press); Markey et al., 2003). Mammary gland development appears to be particularly sensitive to BPA at multiple points in the life span including embryonic development, the perinatal period, puberty and adulthood (Markey et al., 2001, 2003; Wadia et al., 2007), effects which may be mediated by an ER $\alpha$-dependent mechanism (Recchia et al., 2004; Vivacqua et al., 2003). Defects include intraductal hyperplasias, increased sensitivity to endogenous estradiol and the development of neoplastic lesions (Durando et al., 2007).

Like genistein, BPA may also compromise sexual differentiation in the brain. We determined that exposure to $500 \mu \mathrm{g}$ BPA for only 2 days, beginning the day after birth, feminized the number of dopaminergic neurons in the pubertal male rat AVPV (Patisaul et al., 2006) but not the overall size of the AVPV (Patisaul et al., 2007). Another laboratory subsequently reported decreased numbers of dopaminergic neurons in the AVPV of female mice exposed from gestation through lactation to lower, environmentally relevant doses (Rubin et al., 2006). Collectively, these studies suggest that each sex may be susceptible to different doses, a hypothesis that is intriguing and merits further exploration as the observed discrepancy could also be due to differences in, route of administration, duration of exposure or species; all of which illustrates the challenge of translating animal data to human risk assessments. Notably, other studies have also reported phenotypic changes in the AVPV after neonatal exposure to EDCs (Gore, 2008). Exposure to Aroclor 1221, a mixture of PCBs, through late gestation and the early neonatal period reduced the number of ER $\beta$-expressing cells in the adult female rat AVPV without markedly affecting volume (Salama et al., 2003). Similarly, exposure to 2,3,7,8-tetrachlorodibenzo-p-dioxin (TCDD) on gestational day 15 abolished the sexually dimorphic expression of GAD 67 in the rat AVPV on PND 3 (Hays et al., 2002). Although these data support the hypothesis that sexual differentiation of the brain in general, and within the AVPV specifically, may be vulnerable to endocrine disruption, the physiological and functional consequences of these changes has yet to be convincingly established.

Considerable scientific debate remains about whether or not humans are exposed to truly significant levels of BPA. Human serum levels have generally been found to be in the range of $0.2-20 \mathrm{ng} / \mathrm{ml}$ (Vandenberg et al., 2007) and urinary levels increase following the consumption of beverages from polycarbonate bottles containing BPA (Carwile et al., in press). Most rodent studies evaluating potential adverse effects of BPA did not measure serum levels in exposed animals making it difficult to determine if the outcomes can be extrapolated to humans. Further complicating the issue is that humans and rodents metabolize BPA differently, however both species, along with non-human primates, exhibit comparable levels 
of the unconjugated (estrogenically active) form of BPA in fluids and thus perhaps equally susceptible to its effects (reviewed in detail by Vandenberg et al., 2009). Like DDT, the fate of BPA may ultimately be decided by politics and public perception, rather than a regulatory action based on a measured evaluation of the scientific evidence. As this manuscript went to press (May, 2009) Canada declared BPA a "toxin" and Minnesota became the first state to ban the use of BPA in baby bottles and cups. Many other states had similar laws pending. In October of 2008, the Food and Drug Administration reaffirmed its conclusion that BPA use in food containers does not pose a public health threat, a decision that was met with considerable criticism. Not long after, Nalgene and most baby bottle manufacturers announced that they would no longer use BPA in the manufacturing of their products and bottles labeled "BPA-Free" are becoming increasingly common in Wal-Mart and other retail outlets.

\section{ENDOCRINE DISRUPTION OF MALE REPRODUCTIVE PHYSIOLOGY BY DDT AND THE PHTHALATES}

Endocrine disruption can also happen in males. One of the most notable wildlife cases has been documented by researchers at the University of Florida who discovered numerous genital malformations, poor hatching success, and a sex ratio heavily skewed towards females among alligators living in a polluted central Florida lake. This lake had become heavily contaminated with DDT, difocol, their metabolites, and other pesticides as the result of an industrial spill (Guillette et al., 1994, 1995b; Milnes et al., 2005; Semenza et al., 1997). In mammals and birds, gonadal differentiation (the development of either an ovary or testis) is determined by the sex chromosomes. In non-mammalian vertebrates, including reptiles, incubation temperature during a critical window midway through development, influences which gonad forms and thus the sex of the animal. Guillette and colleagues discovered that exposure to estrogens or estrogenic EDCs can override or interact with this effect of temperature resulting in intersex individuals, males with abnormally low plasma testosterone levels, genital abnormalities, and malformation of the gonads (in both sexes). Exposing turtle or alligator eggs experimentally with the DDT metabolite DDE or estradiol induced similar effects (Bergeron et al., 1994; Crews et al., 1995; Gale et al., 2002; Guillette et al., 1995a) conclusively demonstrating that endocrine disruption of male sex determination and the differentiation of the male reproductive system is possible. Reproductive abnormalities within reptiles living on this lake persist, even more than three decades after the initial spill, demonstrating that defects can impact multiple generations, particularly when the compounds are strongly lipophilic and have long half-lives.

In humans, there is growing evidence for, but considerable debate over, whether human male reproductive health is truly declining, and whether EDCs play any role in the perceived decline. In 1992, Carlsen and colleagues conducted a comprehensive review of the literature on human semen quality. Their systematic analysis of 61 published papers, incorporating data collected from nearly 15,000 men, revealed a statistically significant decline in mean seminal volume and sperm concentration over the last 50 years (Carlsen et al., 1992). This finding was widely publicized in the media and subsequently replicated by other investigators, although there appear to be significant regional differences in the severity of the effect (Swan et al., 2000, 2003). Similarly, the incidence of testicular cancer and congenital abnormalities such as hypospadias and cryptorchidism also appear to be increasing (Adami et al., 1994; SEER, 2003; Sharpe, 2003) signifying a comprehensive decline in male reproductive health over the past 50 years. Doubt over the conclusions from these analyses persist however, because reliance on historical data sets (retrospective studies) restricts the ability to control for differences in data collection methods. With this caveat in mind, one feature of the semen data that stands out is an apparent birth cohort effect, with younger generations having poorer semen quality than older generations (Irvine, 1994). This suggests that insult in fetal life could be responsible for the defects that emerge later. This hypothesis is supported by epidemiological data showing that the occurrence of one disorder, such as low sperm count, is a risk factor for the occurrence of another, such as testicular cancer. This relationship has led a Danish research group to propose that low sperm counts, hypospadias, cryptorchidism and testicular germ cell cancer are interrelated disorders, all of which have their roots in fetal development, comprising a "testicular dysgenesis syndrome" (TDS) (Boisen et al., 2001; Skakkebaek et al., 2001, 2006). The TDS hypothesis proposes that these disorders are all manifestations of disturbed prenatal testicular development resulting from abnormal hormone synthesis or action during reproductive tract development.

Androgens, including testosterone, produced by the fetal testes are essential for the differentiation of the epididymis, vas deferens and the seminal vesicles from the Wolffian ducts. Differentiation of the prostate and external genitalia requires $5 \alpha$-dihydrotestosterone (DHT), the most potent androgen produced by the testis catalyzed from testosterone by the enzyme $5 \alpha$-reductase. Failure to produce DHT, or sufficient levels of DHT, can lead to poorly developed or malformed external genitalia. Therefore toxicants that interfere with $5 \alpha$-reductase or the interaction of DHT with the androgen receptor during development can impair proper development of male genitalia and the prostate. For example, administration of the androgen receptor antagonist, flutamide during male reproductive tract development induces multiple abnormalities of the external genitalia including hypospadias and cryptorchidism in both rats and monkeys (Herman et al., 2000; Mylchreest et al., 1999). Environmental toxicants are also known to interfere with male genital development. One of the earliest animal studies designed to test the hypothesis that chemical agents could interfere with androgen action was conducted in 1950 using chickens. Injection of DDT resulted in markedly undersized testes and inhibited the development of the comb and wattle. It was later determined that DDT and its metabolites function as anti-androgens (as well as estrogen mimics) and compete with endogenous androgens for access to the androgen receptor.

One class of compounds that has recently received considerable attention for potentially contributing to TDS is the phthalates. There are many different kinds of phthalates and the two considered to have the greatest potential to impact male reproduction are dibutyl phthalate (DBP) and diethylhexyl phthalate (DEHP, Figure 1). DBP is used in many personal care products such as lotions, cosmetics, nail polish, and perfume. DEHP is primarily used as a plasticizer in the production of flexible products including vinyl, medical tubing and toys. Infants in neonatal intensive care units have some of the highest urinary phthalate levels observed to date, presumably 
a result of exposure through medical tubing and devices (Calafat et al., 2004; Weuve et al., 2006). A series of studies conducted in rats in the late 1990s was the first to demonstrate that phthalates could interfere with the ability of testosterone to masculinize the male reproductive tract. Exposure in utero, when the genitals are being formed, resulted in a number of genital malformations including hypospadias and hemorrhagic testes (Gray et al., 1999; Wolf et al., 2000). Thus it is plausible that neonatal exposure to phthalates could induce TDS. Interestingly, the phthalates do not produce their effects by antagonizing the androgen receptor, but rather by interfering with the production of androgens in the fetal testis (David, 2006). Exposure to phthalates during human pregnancy has now been associated with smaller (feminized) anogenital distance in infant boys (Swan et al., 2005). Epidemiological evidence has also positively correlated higher urinary phthalate levels with lower sperm counts and an increased likelihood of sperm with damaged DNA in adult men (Duty et al., 2003; Hauser, 2008; Pant et al., 2008; Wirth et al., 2008). Although it is important to keep in mind that correlation does not prove causation, these newly emerging epidemiology studies are the best evidence to data that phthalates have the potential to affect male reproductive health in humans.

\section{MIXTURE EFFECTS: WHEN THE QUALITY OF BIRD SONG CONSTITUTES "FALSE ADVERTISING"}

Intriguingly, exposure to EDCs can also enhance the masculinization of some traits but this many not translate to improved reproductive fitness. A good example of this occurred in song birds exposed to a mixture of compounds including phthalates. In song birds, song production is controlled by discrete neural pathways which develop and operate under the influence of steroid hormones. Estrogens, as well as androgens to some degree, are essential for proper sex specific organization of the song system. According to sexual selection theory, male secondary sex characteristics, including the production of elaborate songs, have evolved as indicators of male quality and in response to female preferences. Thus, modification of the song system by exposure to estrogenic contaminants could affect song quality and, as a result, how attractive exposed males are to potential mates. A recent experiment by Markman and colleagues tested this hypothesis using European starlings (Sturnus vulgaris) (Markman et al., 2008). The research group first observed the foraging habits of wild starlings at 20 sewage treatment sites and determined that earthworms were a primary prey species. Subsequent analysis of these earthworms revealed that they were heavily contaminated with $17 \beta$-estradiol (E2, from human wastewater), phthalates and BPA. A daily exposure for each compound was then estimated. Wild-caught juvenile birds were then maintained in the laboratory and exposed to either vehicle, $200 \mathrm{ng}$ E2 or the environmentally relevant mixture (200 ng E2, $640 \mathrm{ng}$ phthalates, $80 \mathrm{ng} \mathrm{BPA}$ ) daily by injecting each preparation into a mealworm. The birds were exposed from October to April, when foraging on sewage beds is common, prior to the onset of the breeding season in the spring. Males exposed to the mixture had significantly enhanced song production including a more complex song repertoire, an increased number of song bouts, and longer songs. This was accompanied by enlargement of an important song nucleus, the $\mathrm{HVC}$, in the males fed the mixture compared to control males.
Females preferred the song of males fed the mixture to males fed either the vehicle or the E2 alone.

Enhanced song production, however, in this case appears to be a false indicator of male quality because subsequent analysis found that, even though circulating androgen levels were comparable to controls, the males fed the mixture were immunocompromised. Thus, although EDCs enhanced the masculinization of the song system, by misleading females into choosing less fit males the effect could subsequently decrease the overall fitness of the population.

Interestingly, males fed only E2 did not show enhanced song production or larger song nuclei demonstrating that this component of the mixture was insufficient on its own to influence this estrogen sensitive behavior. This finding emphasizes the concern that although some estrogenic compounds may not produce effects at low levels on their own, they may ultimately contribute to disruption when contained within a mixture of compounds with similar mechanisms of action. This concern is potentially considerable for a number of reasons. Perhaps one of the most worrisome is that, because most laboratory animal diets are derived from soy and therefore contain relatively high levels of genistein and other phytoestrogens (actual amounts vary from batch to batch) this background of EDC exposure could impact endocrine disruption research (Brown and Setchell, 2001; Degen et al., 2002). Could this be a significant potential confound? A research group at Washington State University recently reported that they could not replicate previously published BPA effects in the mouse ovary. They ultimately concluded that effects were only observed in mice maintained on soy-rich diets leading the authors to hypothesize that diet, along with methodological differences, could explain why the literature surrounding "low dose" effects of BPA is fragmented and inconsistent (Muhlhauser et al., 2009). The concept of mixture effects is an evolving area of endocrine disruption research, the results of which could have profound implications for other disciplines including neuroendocrinology and behavioral biology.

\section{TRANSGENERATIONAL EFFECTS AND THE EMERGING FIELD OF EPIGENETICS}

It is now becoming evident that the effects of EDC exposure are not necessarily limited to the exposed individual. Many of these compounds are now recognized to have transgenerational effects and in some cases the effects within subsequent generations are more profound than those seen in the first generation (Jirtle and Skinner, 2007; Steinberg et al., 2008). For example, there is emerging concern that the children of DES daughters (referred to as DES granddaughters) might also experience reproductive problems. For these girls, their exposure occurred when they were germ cells in their mother's developing ovary, within the womb of their grandmother. If true, it would be the first instance in humans which conclusively demonstrates that persistent, generational effects can result from an in utero exposure to a potent estrogen (Newbold et al., 1998). This concern for DES granddaughters arose from data obtained in laboratory animal studies which indicated that the offspring of females exposed in utero were more likely to develop reproductive tract lesions than unexposed control animals (Newbold et al., 1998, 2000). Other studies have produced evidence that DES effects across generations can be transmitted through the paternal line as well (Walker and Haven, 1997). So far, there is not enough human data 
to indicate a trend for deleterious effects in DES granddaughters, largely because this cohort is so young. Continued monitoring of these women as they age will ultimately be required to determine if there are transgenerational effects of prenatal DES exposure in humans.

The precise mechanisms through which endocrine disrupting effects transmit to subsequent generations are not well understood but emerging evidence indicates alteration of chromosomal structure or other epigenetic mechanisms might be the primary method. Epigenetic inheritance involves changes in gene expression patterns without changes in gene sequence. Such effects include DNA methylation and histone modifications, among others. In most cases, methylation of gene promoter regions abrogates gene transcription while acetylation of the histone tail enhances it (Dolinoy et al., 2007; Gore, 2008; Ho and Tang, 2007). These processes can be influenced by environmental factors and if these modifications occur within the germ cell lines then transmission to subsequent generations is possible (Giusti et al., 1995; Gore, 2008; Jirtle and Skinner, 2007). This newly discovered and evolving area of research has once again transformed the field of toxicology and introduced a novel method by which endocrine disruptors and other toxicants can affect vertebrate physiology and behavior.

A well characterized animal model demonstrating the potential for epigenetic modifications to impact future generations involves the manipulation of the murine agouti gene in a specialized mouse strain (Duhl et al., 1994; Vrieling et al., 1994). In this strain, the degree of methylation on an inserted transposable element can vary dramatically and correlates with a wide distribution in coat color that ranges from yellow (unmethylated) to brown (methylated) as well as the occurrence of diabetes, obesity and tumorigenesis. Maternal dietary supplementation of methyl-donors (folic acid, vitamin $\mathrm{B}_{12}$, choline and betaine) during pregnancy can shift the coat color of offspring towards the brown pseudoagouti phenotype (Duhl et al., 1994; Waterland and Jirtle, 2003; Wolff et al., 1998) demonstrating the effect maternal diet can have on offspring adult phenotypes. Even more intriguing is the observation that maternal exposure to genistein induces hypermethylation, again shifting the coat color of the offspring to brown (Dolinoy et al., 2006), but unlike other methyl donors, genistein protected these offspring from the obesity normally associated with the darker color. These results illustrate the potential for genistein and perhaps other EDCs to epigenetically alter the phenotype of subsequent generations through in utero exposure. Other compounds, including polychlorinated biphenyls (PCBs) (Aubrecht et al., 1995; Schiestl et al., 1997) and the fungicide vinclozolin (Anway et al., 2006; Gore, 2008) have also been shown to produce transgenerational effects, perhaps through epigenetic mechanisms.

When a pregnant animal is exposed to an EDC, it is important to keep in mind that the mother $\left(\mathrm{F}_{0}\right)$, the embryo $\left(\mathrm{F}_{1}\right)$ and the $\mathrm{F}_{2}$ generation (as germ cells) are all directly exposed. While the majority of studies concerning transgenerational epigenetic effects of EDCs have not been carried past the $\mathrm{F}_{2}$ generation it is important to note that, to rule out direct exposure effects, the $\mathrm{F}_{3}$ generation should also be examined for abnormalities. It is also critical to appreciate that epigenetic effects can also occur outside of the germ line. Thus these mechanisms may underlie many observed EDC effects and could explain how compounds which are only weakly estrogenic, like BPA, can produce appreciable, lasting results at such low levels (Jirtle and Skinner, 2007). The ability of most estrogenic EDCs, such as DES, genistein and BPA, to pass from mother to offspring through placental blood flow or lactational transfer makes the possibility for epigenetic, transgenerational effects likely (Crews and McLachlan, 2006; Franke and Custer, 1996; Mably et al., 1992; Newbold, 2006; Ruden et al., 2005; Sun et al., 2004; Wisniewski et al., 2003). Although the specific mechanisms underlying the observed transgenerational effects of DES in animals have proven difficult to elucidate, emerging research implicates epigenetic modifications as a significant component (Gore, 2008; Li et al., 2003; Newbold, 2006). Newbold and colleagues have recently shown that alterations in gene methylation patterns of estrogen-responsive genes following DES exposure can be passed on to the next generation (Li et al., 1997, 2003; Newbold, 2006). Studies exploring how epigenetics might explain the "fetal origins of adult disease" are currently underway in DES granddaughters, but results will emerge slowly because of the relatively young age of the subjects. Although clear indicators of illness occurred early in some individuals, most carcinogenic and reproductive tract abnormalities in DES daughters did not occur until at least middle age and it will be another decade before most of the DES granddaughters reach that age as well. Thus, many transgenerational effects in these individuals have likely not yet emerged (Giusti et al., 1995; Rubin, 2007).

\section{CONCLUSIONS}

While it appears clear, in both animals and humans, that exposure to EDCs can have adverse effects on reproductive physiology and behavior, controversies surrounding this topic remain. Importantly, recognition of the prevalence of these compounds in the environment and their potential to adversely affect both wildlife and human populations is increasing among scientists, policy makers, and the general public. Further efforts to understand the mechanisms underlying EDC effects, particularly those seen at environmentally relevant doses by compounds with low hormonal potency, are necessary to adequately develop a public health strategy for preventing or combating their effects. The ability of these compounds to permanently affect the epigenome could be potentially catastrophic to the welfare of future generations and requires further attention by both toxicologists and endocrinologists. While research surrounding this topic is not conclusive, particularly in humans, there is certainly sufficient evidence to warrant concern about potential long term effects in both wildlife and humans. Obtaining absolute proof of endocrine disruption by BPA, phthalates, and other compounds with weak hormonal activity in humans is likely impossible because it would obviously be unethical to conduct a double-blind study where one group is exposed to a suspected toxicant. Research in animals, however, is robust and indicates that disruption of sex specific behavior, neuroendocrine circuitry and physiology is possible and, in some cases, transgenerational.

Unfortunately, it is extraordinarily difficult for individuals to make informed choices about how to reduce their potential exposure because chemicals in the US are not routinely screened or tested for endocrine disrupting properties. The Endocrine Disruptor Screening and Testing Advisory Committee (EDSTAC) was formed by Congress in 1996 to make specific recommendations to the EPA about how to test and screen compounds for endocrine disrupting properties, but progress has been frustratingly slow. 
A list of compounds to be screened was not compiled until April of 2009 and only 67 chemicals were included, a tiny fraction of the thousands of compounds now suspected of having endocrine disrupting properties. Moreover, it is often impossible to determine which plastics, cosmetics, toys, or other household items contain any of these compounds so consumers have no adequate way to avoid them if desired. The thought that the mixture of chemicals a pregnant woman is exposed to during her pregnancy could affect not only her daughter's fecundity but also her granddaughter's is alarming and a major reason why the topic of endocrine

\section{REFERENCES}

Adachi, S., Yamada, S., Takatsu, Y., Matsui, H., Kinoshita, M., Takase, K., Sugiura,H.,Ohtaki, T.,Matsumoto, H., Uenoyama, Y., Tsukamura, H., Inoue, K., and Maeda, K. (2007). Involvement of anteroventral periventricular metastin/ kisspeptin neurons in estrogen positive feedback action on luteinizing hormone release in female rats. J. Reprod. Dev. 53, 367-378.

Adami, H. O., Bergstrom, R., Mohner, M., Zatonski, W., Storm, H., Ekbom, A., Tretli, S., Teppo, L., Ziegler, H., Rahu, M., Rahu M., Gurevicius, R., and Stengrevics, A. (1994). Testicular cancer in nine northern European countries. Int. J. Cancer. 59, 33-38.

Adams, N. R. (1995a). Detection of the effects of phytoestrogens on sheep and cattle. J. Anim. Sci. 73, 1509-1515.

Adams, N. R. (1995b). Organizational and activational effects of phytoestrogens on the reproductive tract of the ewe. Proc. Soc. Exp. Biol. Med. 208, 87-91.

Adewale, H.B., Jefferson, W.N., Newbold, R R., Patisaul, H.B. (in press). Neonatal bisphenol-a exposure alters rat reproductive development and ovarian morphology without impairing activation of gonadotropin releasing hormone neurons. Biol. Reprod. doi: 10.1095/biolreprod.109.078261.

Adlercreutz, H., and Mazur, W. (1997). Phyto-oestrogens and western diseases. Ann. Med. 29, 95-120.

Aksglaede, L., Sorensen, K., Petersen, J.H., Skakkebaek, N. E., and Juul,A. (2009). Recent decline in age at breast development: the Copenhagen Puberty Study. Pediatrics 123, e932-e939.

Andersen, M. E., Conolly, R. B., Faustman, E. M., Kavlock, R. J., Portier, C. J., Sheehan, D. M., Wier, P. J., and Ziese, L. (1999). Quantitative mechanistically based dose-response modeling with endocrine-active compounds. Environ. Health Perspect. 107(Suppl. 4), 631-638.

Anway, M. D., Leathers, C., and Skinner, M. K. (2006). Endocrine disruptor vinclozolin induced epigenetic transgenerational adult-onset disease. Endocrinology 147, 5515-5523.

Aubrecht, J., Rugo, R., and Schiestl, R. H. (1995). Carcinogens induce intrachromosomal recombination in human cells. Carcinogenesis 16, 2841-2846.

Axelson, M., Sjovall, J., Gustafsson, B. E., and Setchell K. D. (1982). Origin of lignans in mammals and identification of a precursor from plants. Nature 298, 659-660.

Bakker, J., and Baum, M. J. (2008). Role for estradiol in female-typical brain and behavioral sexual differentiation. Front. Neuroendocrinol. 29, 1-16.

Balthazart, J., Tlemcani, O., and Ball, G. F. (1996). Do sex differences in the brain explain sex differences in the hormonal induction of reproductive behavior? What 25 years of research on the Japanese quail tells us. Horm. Behav. 30, 627-661.

Barnes, S. (1995). Effect of genistein on in vitro and in vivo models of cancer. $J$. Nutr. 125(Suppl. 3), S777-S783.

Bateman, H. L., and Patisaul,H. B. (2008). Disrupted female reproductive physiology following neonatal exposure to phytoestrogens or estrogen specific ligands is associated with decreased $\mathrm{GnRH}$ activation and kisspeptin fiber density in the hypothalamus. Neurotoxicology 29, 988-997.

Baum, M. J. (1979). Differentiation of coital behavior in mammals: a comparative analysis. Neurosci. Biobehav. Rev. 3, 265-284.

Beans, B. E. (1996). Eagle's Plume: The Struggle to Preserve the Life and Haunts of America's Bald Eagle. Lincoln, University of Nebraska Press.

Beard, J. (2006). DDT and human health. Sci. Total Environ. 355, 78-89.

Bennetts,H.H.W., and Underwood, E. E. J. subterranean clover (trifolium subterraneum); uterine maintenance in the ovariectomised ewe on clover grazing. Aust J. Exp. Biol. Med. Sci. 29, 249-253.

Bennetts, H. W., Underwood, E. J., and Shier, F. L. (1946). A specific breeding problem of sheep on subterranean (1951). The oestrogenic effects of

disruption continues to receive global attention by scientists and the general public.

\section{ACKNOWLEDGEMENTS}

The authors are grateful to the editors for providing us the opportunity to summarize this research in this special issue. We also thank Karina Todd and Jillian Mickens for their critical reading of this manuscript and assistance with some of the research described in the text. Funding provided by: NIEHS grant R01 ES016001 to H. Patisaul.

clover pastures in Western Australia. Aust. Vet. J. 22, 2.

Bergeron, J. M., Crews, D., and McLachlan, J. A. (1994). PCBs as environmental estrogens: turtle sex determination as a biomarker of environmental contamination. Environ. Health Perspect. 102, 780-781.

Boisen, K. A., Main, K. M., Rajpert-De Meyts, E., and Skakkebaek, N. E. (2001). Are male reproductive disorders a common entity? The testicular dysgenesis syndrome. Ann. N.Y.Acad. Sci. 948, 90-99.

Boutin, J. A. (1994). Minireview - tyrosine protein kinase inhibition and cancer. Int. J. Biochem. Cell Biol. 26 , 1203-1226.

Braden, A., Hart, N., and Lamberton, J. (1967). Oestrogenic activity and metabolism of certain isoflavones in sheep. Aust. J. Agric. Res. 18, 348-355.

Brannian, J., and Hansen, K. (2006). Assisted reproductive technologies in South Dakota: the first ten years. S. $D$. Med. 59, 291-293.

Brede, C., Fjeldal, P., Skjevrak, I., and Herikstad, H. (2003). Increased migration levels of bisphenol A from polycarbonate baby bottles after dishwashing, boiling and brushing. Food Addit. Contam. 20, 684-689.

Brown, N. M., and Setchell, K. D. (2001) Animal models impacted by phytoestrogens in commercial chow: implications for pathways influenced by hormones. Lab. Invest. 81, 735-747.

Calabrese,E. J.(2001).Estrogen and related compounds: biphasic dose responses. Crit. Rev. Toxicol. 31, 503-515.

Calabrese, E. J., and Baldwin, L. A. (2003). Toxicology rethinks its central belief. Nature 421, 691-692.

Calafat, A. M., Kuklenyik, Z., Reidy, J. A., Caudill, S. P., Ekong, J., and Needham, L. L. (2005). Urinary concentrations of bisphenol A and 4-nonylphenol in a human reference population. Environ. Health Perspect. 113, 391-395.

Calafat, A. M., Needham, L. L., Silva, M. J., and Lambert, G. (2004). Exposure to di-(2-ethylhexyl) phthalate among premature neonates in a neonatal intensive care unit. Pediatrics 113, e429-e434.

Calafat, A. M., Weuve, J., Ye, X., Jia, L. T., $\mathrm{Hu}, \mathrm{H}$., Ringer, S., Huttner, K., and Hauser, R. (2009). Exposure to bisphenol $\mathrm{A}$ and other phenols in neonatal intensive care unit premature infants. Environ. Health Perspect. 117, 639-644.

Calafat, A. M., Ye, X., Wong, L. Y., Reidy, J. A., and Needham, L. L. (2008). Exposure of the U.S. population to bisphenol A and 4-tertiary-octylphenol: 2003-2004. Environ. Health Perspect. 116, 39-44.

Cao, Y., Calafat, A. M., Doerge, D. R., Umbach, D. M., Bernbaum, J. C. Twaddle, N.C., Ye, X., and Rogan, W. J. (2009). Isoflavones in urine, saliva, and blood of infants: data from a pilot study on the estrogenic activity of soy formula. J. Expo. Sci. Environ. Epidemiol. 19, 223-234.

Carlsen, E., Giwercman, A., Keiding, N., and Skakkebaek, N.E.(1992). Evidence for decreasing quality of semen during past 50 years. BMJ 305, 609-613.

Carwile, J. L., Luu, H. T., Bassett, L. S. Driscoll,D.A., Yuan, C., and Chang, J. Y. (in press). Use of polycarbonate bottles and urinary bisphenol a concentrations. Environ. Health Perspect. doi: 10.1289/EHP.0900604.

Clapp, R. W., Jacobs, M. M., and Loechler, E. L. (2008). Environmental and occupational causes of cancer: new evidence 2005-2007. Rev. Environ. Health 23, 1-37.

Clarke, I. J., and Pompolo, S. (2005). Synthesis and secretion of GnRH. Anim. Reprod. Sci. 88, 29-55.

Clarkson, J., d'Anglemont de Tassigny, X. Moreno, A. S., Colledge, W. H., and Herbison, A. E. (2008). KisspeptinGPR54 signaling is essential for preovulatory gonadotropin-releasing hormone neuron activation and the luteinizing hormone surge. J. Neurosci. 28, 8691-8697.

Clarkson, T. B. (2002). Soy, soy phytoestrogens and cardiovascular disease. J. Nutr. 132, 566S-569S.

Cohn, B. A., Wolff, M. S., Cirillo, P. M. and Sholtz, R. I. (2007). DDT and breast cancer in young women: new 
data on the significance of age at exposure. Environ. Health Perspect. 115, 1406-1414.

Cooke, B., Hegstrom, C. D., Villeneuve, L. S., and Breedlove, S. M. (1998). Sexual differentiation of the vertebrate brain: principles and mechanisms. Front. Neuroendocrinol. 19, 323-362.

Crain, D. A., Eriksen, M., Iguchi, T., Jobling, S., Laufer, H., LeBlanc, G. A., and Guillette, L. J. (2007). An ecological assessment of bisphenol-A: evidence from comparative biology. Reprod. Toxicol. 24, 225-239.

Crews, D., Bergeron, J. M., and McLachlan, J. A. (1995). The role of estrogen in turtle sex determination and the effect of PCBs. Environ. Health Perspect. 103(Suppl. 7), 73-77.

Crews, D., and McLachlan, J. A. (2006). Epigenetics, evolution, endocrine disruption, health, and disease. Endocrinology 147, s4-s10.

Crisp, T. M., Clegg, E. D., Cooper, R. L., Wood, W. P., Anderson, D. G., Baetcke, K. P., Hoffmann, J. L., Morrow, M. S., Rodier, D. J., Schaeffer, J. E., Touart, L. W., Zeeman, M.G., and Patel,Y.M. (1998). Environmental endocrine disruption: an effects assessment and analysis. Environ. Health Perspect. 106(Suppl. 1), 11-56.

Crump, K. (2001). Evaluating the evidence for hormesis: a statistical perspective. Crit. Rev. Toxicol. 31, 669-679.

David, R. M. (2006). Proposed mode of action for in utero effects of some phthalate esters on the developing male reproductive tract. Toxicol. Pathol. 34, 209-219.

Davidson, J. M., and Bloch, G. J. (1969). Neuroendocrine aspects of male reproduction. Biol. Reprod. 1(Suppl. 1), 67-92.

Degen, G. H., Janning, P., Diel, P., and Bolt, H. M. (2002). Estrogenic isoflavones in rodent diets. Toxicol. Lett. 128, 145-157.

Demonty, I., Lamarche, B., and Jones, P. J. (2003). Role of isoflavones in the hypocholesterolemic effect of soy. Nutr. Rev. 61, 189-203.

Dodds, E. C., Goldberg, L., Larson, W., and Robinson, R. (1938). Estrogenic activity of certain synthetic compounds. Nature 141, 247.

Dodds, E. C., and Lawson, W. (1936). Synthetic estrogen agents without the phenanthrene nucleus. Nature 137, 996.

Dolinoy, D. C., Weidman, J. R., and Jirtle, R. L. (2007). Epigenetic gene regulation: linking early developmental environment to adult disease. Reprod. Toxicol. 23, 297-307.

Dolinoy, D. C., Weidman, J. R., Waterland, R. A., and Jirtle, R. L.
(2006). Maternal genistein alters coat color and protects Avy mouse offspring from obesity by modifying the fetal epigenome. Environ. Health Perspect. 114, 567-572.

Duhl, D. M., Vrieling, H., Miller, K. A., Wolff, G. L., and Barsh, G. S. (1994). Neomorphic agouti mutations in obese yellow mice. Nat. Genet. 8 , 59-65.

Durando, M., Kass, L., Piva, J., Sonnenschein, C., Soto, A. M., Luque, E. H., and Muñoz-deToro, M. (2007). Prenatal bisphenol A exposure induces preneoplastic lesions in the mammary gland in Wistar rats. Environ. Health Perspect. $115,80-86$.

Duty, S. M., Singh, N. P., Silva, M. J., Barr, D. B., Brock, J. W., Ryan, L., Herrick, R. F., Christiani, D. C., and Hauser, R. (2003). The relationship between environmental exposures to phthalates and DNA damage in human sperm using the neutral comet assay. Environ. Health Perspect. 111, 1164-1169.

Elkind-Hirsch, K., King, J. C., Gerall, A. A., and Arimura, A. A. (1981). The luteinizing hormone-releasing hormone (LHRH) system in normal and estrogenized neonatal rats. Brain Res. Bull. 7, 645-654.

Faber, K., Jones, M., and Tarraza, H. M. (1990). Invasive squamous cell carcinoma of the vagina in a diethylstilbestrol-exposed woman. Gynecol. Oncol. 37, 125-128.

Fletcher, R. (2003). Food sources of phyto-estrogens and their precursors in Europe. Br. J. Nutr. 89(Suppl. 1), S39-S43.

Food and Drug Administration (1999). Food labeling: health claims; soy protein and coronary heart disease. Food and Drug Administration, HHS. Final rule. Fed Regist. 64, 57700-57733.

Franke, A., Custer, L., Wang, W., and Yang, S. C. (1998a). HPLC analysis of isoflavonoids and other phenolic agents from foods and from human fluids. Proc. Soc. Exp. Biol. Med. 217, 263-272.

Franke, A. A., Custer, L. J., and Tanaka, Y. (1998b). Isoflavones in human breast milk and other biological fluids. Am. J. Clin. Nutr. 68(Suppl. 6), 1466S-1473S.

Franke, A. A., and Custer, L. J. (1996). Daidzein and genistein concentrations in human milk after soy consumption. Clin. Chem. 42, 955-964.

Freni-Titulaer, L. L. W., Cordero, J. J. F., Haddock, L. L., Lebrón, G. G., Martínez, R.R., and Mills,J.J.L. (1986). Premature thelarche in Puerto Rico. A search for environmental factors. Am. J. Dis. Child. 140, 1263-1267.
Frey, K. A., and Patel, K. S. (2004). Initial evaluation and management of infertility by the primary care physician. Mayo Clin. Proc. 79, 1439-1443; quiz 1443.

Gale, R. W., Bergeron, J. M. Willingham, E. J., and Crews, D (2002). Turtle sex determination assay: mass balance and responses to 2,3,7,8-tetrachlorodibenzo-pdioxin and 3,3',4,4',5-pentachlorobiphenyl. Environ. Toxicol. Chem. 21 , 2477-2482.

Gerall, A. A. (1967). Effects of early postnatal androgen and estrogen injections on the estrous activity cycles and mating behavior of rats. Anat. Rec. 157, 97-104.

Gill, W. B., Schumacher, G. F., and Bibbo, M. (1976). Structural and functional abnormalities in the sex organs of male offspring of mothers treated with diethylstilbestrol (DES). J. Reprod. Med. 16, 147-153.

Giusti, R. M., Iwamoto, K., and Hatch, E. E. (1995). Diethylstilbestrol revisited: a review of the long-term health effects. Ann. Intern. Med. 122, 778-788.

Gore, A. C. (2008). Developmental programming and endocrine disruptor effects on reproductive neuroendocrine systems. Front. Neuroendocrinol. 29, 358-374.

Gorski, R. A. (1963). Modification of ovulatory mechanisms by postnatal administration of estrogen to the rat. Am. J. Physiol. 205, 842-844.

Gorski, R.A. (1985). Sexual dimorphisms of the brain. J. Anim. Sci. 61(Suppl.3), 38-61.

Gorski, R. A., Mennin, S. P., and Kubo, K. (1975). The neural and hormonal bases of the reproductive cycle of the rat. Adv. Exp. Med. Biol. 54, 115-153.

Gottsch, M. L., Cunningham, M. J., Smith, J. T., Popa, S. M., Acohido, B. V., Crowley, W. F., Seminara, S., Clifton, D. K., and Steiner, R. A. (2004). A role for kisspeptins in the regulation of gonadotropin secretion in the mouse. Endocrinology 145, 4073-4077.

Gould, J. C., Leonard, L. S., Maness, S.C., Wagner, B. L., Conner, K., Zacharewski, T., Safe, S., McDonnell, D. P., and Gaido, K. W. (1998). Bisphenol A interacts with the estrogen receptor alpha in a distinct manner from estradiol. Mol. Cell. Endocrinol. 142, 203-214.

Goy, R. W., and Resko, J. A. (1972). Gonadal hormones and behavior of normal and pseudohermaphroditic nonhuman female primates. Recent. Prog. Horm. Res. 28, 707-733.

Grady, K. L., Phoenix, C. H., and Young, W. C. (1965). Role of the developing rat testis in differentiation of the neural tissues mediating mating behavior.J. Comp. Physiol. Psychol. 59, 176-182.

Gray, L. E. Jr., Wolf, C., Lambright, C., Mann, P., Price, M., Cooper, R. L., and Ostby, J. (1999). Administration of potentially antiandrogenic pesticides (procymidone, linuron, iprodione, chlozolinate, p, p'-DDE, and ketoconazole) and toxic substances (dibutyland diethylhexyl phthalate, PCB 169, and ethane dimethane sulphonate) during sexual differentiation produces diverse profiles of reproductive malformations in the male rat. Toxicol. Ind. Health 15, 94-118.

Gu, G. B., and Simerly, R. B. (1997). Projections of the sexually dimorphic anteroventral periventricular nucleus in the female rat. J. Comp. Neurol. 384, 142-164.

Guillette, L. J. Jr., Crain, D. A., Rooney, A. A., and Pickford, D. B. (1995a). Organization versus activation: the role of endocrine-disrupting contaminants (EDCs) during embryonic development in wildlife. Environ. Health Perspect. 103(Suppl.7), 157-164.

Guillette, L. J. Jr., and Gunderson, M. P. (2001). Alterations in development of reproductive and endocrine systems of wildlife populations exposed to endocrine-disrupting contaminants. Reproduction 122, 857-864.

Guillette, L. J.J., Gross, T. S., Masson, F. R., Matter, J. M., Percival, J. F., and Woodward, A. R. (1994). Developmental abnormalities of the gonad and abnormal sex hormone concentrations in juvenile alligators from contaminated and control lakes in Florida. Environ. Health Perspect. 102, 680-688.

Guillette, L. J. J., Pickford, D., Crain, D., Rooney, A., and Percival, H. (1995b). Reduction in penis size and plasma testosterone concentrations in juvenile alligators living in a contaminated environment. Gen. Comp. Endocrinol. $101,32-42$.

Hauser, R. (2008). Urinary phthalate metabolites and semen quality: a review of a potential biomarker of susceptibility. Int. J. Androl. 31, 112-117.

Hayes, T., Haston, K., Tsui, M., Hoang, A., Haeffele, C., and Vonk, A. (2002). Herbicides: feminization of male frogs in the wild. Nature 419, 895-896.

Hays, L. E., Carpenter, C. D., and Petersen, S. L. (2002). Evidence that GABAergic neurons in the preoptic area of the rat brain are targets of 2,3,7,8-tetrachlorodibenzo-p-dioxin during development. Environ. Health Perspect. 110(Suppl. 3), 369-376.

Herbison, A. E., and Pape, J. R. (2001). New evidence for estrogen receptors 
in gonadotropin-releasing hormone neurons. Front. Neuroendocrinol. 22, 292-308.

Herbst, A. L., Green, T. H. Jr., and Ulfelder, H. (1970). Primary carcinoma of the vagina. An analysis of 68 cases. Am. J. Obset. Gynecol. 106, 210-218.

Herbst, A. L., Ulfelder, H., and Poskanzer, D. C. (1971). Adenocarcinoma of the vagina. Association of maternal stilbestrol therapy with tumor appearance in young women. N. Engl. J. Med. 284, 878-881.

Herman-Giddens, M. E., Slora, E. J., Wasserman, R. C., Bourdony, C. J., Bhapkar, M. V., Koch, G. G., and Hasemeier, C. M. (1997). Secondary sexual characteristics and menses in young girls seen in office practice: a study from the Pediatric Research in Office Settings network. Pediatrics 99, 505-512.

Herman, R. A., Jones, B., Mann, D. R., and Wallen, K. (2000). Timing of prenatal androgen exposure: anatomical and endocrine effects on juvenile male and female rhesus monkeys. Horm. Behav. 38, 52-66

Ho, S. M., and Tang, W. Y. (2007). Techniques used in studies of epigenome dysregulation due to aberrant DNA methylation: an emphasis on fetal-based adult diseases. Reprod. Toxicol. 23, 267-282.

Honma, S., Suzuki, A., Buchanan, D. L., Katsu, Y., Watanabe, H., and Iguchi, T. (2002). Low dose effect of in utero exposure to bisphenol A and diethylstilbestrol on female mouse reproduction. Reprod. Toxicol. 16, 117-122.

Hrabovszky, E., Shughrue, P. J., Merchenthaler, I., Hajszan, T., Carpenter, C. D., Liposits, Z., and Petersen, S. L. (2000). Detection of estrogen receptor-beta messenger ribonucleic acid and 125I-estrogen binding sites in luteinizing hormone-releasing hormone neurons of the rat brain. Endocrinology 141, 3506-3509.

Hrabovszky, E., Steinhauser, A., Barabas, K., Shughrue, P. J., Petersen, S. L., Merchenthaler, I., and Liposits, Z. (2001). Estrogen receptorbeta immunoreactivity in luteinizing hormone-releasing hormone neurons of the rat brain. Endocrinology 142, 3261-3264.

Ikezuki, Y., Tsutsumi, O., Takai, Y., Kamei, Y., and Taketani, Y. (2002). Determination of bisphenol A concentrations in human biological fluids reveals significant early prenatal exposure. Hum. Reprod. 17, 2839-2841.

Irvine, D. S. (1994). Falling sperm quality. BMJ 309, 476.
Irwig, M. S., Fraley, G. S., Smith, J. T., Acohido, B. V., Popa, S. M. Cunningham, M. J., Gottsch, M. L., Clifton, D. K., and Steiner, R. A. (2004). Kisspeptin activation of gonadotropin releasing hormone neurons and regulation of KiSS-1 mRNA in the male rat. Neuroendocrinology 80 , 264-272.

Jefferson, W. N., Couse, J. F., PadillaBanks, E., Korach, K. S., and Newbold, R. R. (2002). Neonatal exposure to genistein induces estrogen receptor (ER)alpha expression and multioocyte follicles in the maturing mouse ovary: evidence for ERbetamediated and nonestrogenic actions. Biol. Reprod. 67, 1285-1296.

Jefferson, W. N., Padilla-Banks, E., and Newbold, R. R. (2005). Adverse effects on female development and reproduction in CD-1 mice following neonatal exposure to the phytoestrogen genistein at environmentally relevant doses. Biol. Reprod. 73, 798-806.

Jefferson, W. N., Padilla-Banks, E., and Newbold, R. R. (2006). Studies of the effects of neonatal exposure to genistein on the developing female reproductive system. J. AOAC Int. 89, 1189-1196.

Jefferson, W. N., Padilla-Banks, E., and Newbold, R. R. (2007). Disruption of the female reproductive system by the phytoestrogen genistein. Reprod. Toxicol. 23, 308-316.

Jirtle, R. L., and Skinner, M. K. (2007). Environmental epigenomics and disease susceptibility. Nat. Rev. Genet. 8, 253-262.

Joensen, U. N., Jorgensen, N., RajpertDe Meyts, E., and Skakkebaek, N. E. (2008). Testicular dysgenesis syndrome and Leydig cell function. Basic Clin. Pharmacol. Toxicol. 102, 155-161.

Johns, P., Dowlati, L., and Wargo, W. (2003). Determination of isoflavones in ready-to-feed soy-based infant formula. J. AOAC Int. 86, 72-78.

Karnaky, K. J. (1953). Diethylstilbestrol therapy; long period and high dosage Des therapy. Med. Times 81, 315-317.

Kauffman, A. S., Clifton, D. K., and Steiner, R. A. (2007a). Emerging ideas about kisspeptin- GPR54 signaling in the neuroendocrine regulation of reproduction. Trends Neurosci. 30, 504-511.

Kauffman, A. S., Park, J. H., McPhieLalmansingh, A. A., Gottsch, M. L., Bodo, C., Hohmann, J. G., Pavlova, M. N., Rohde, A. D., Clifton, D. K., Steiner, R. A., and Rissman, E.F. (2007b). The kisspeptin receptor GPR54 is required for sexual differentiation of the brain and behavior. J. Neurosci. 27, 8826-8835.

Komisaruk, B. R., and Diakow, C. (1973). Lordosis reflex intensity in rats in rela- tion to the estrous cycle, ovariectomy, estrogen administration and mating behavior. Endocrinology 93, 548-557.

Korach, K. S., Metzler, M., and McLachlan, J. A. (1978). Estrogenic activity in vivo and in vitro of some diethylstilbestrol metabolites and analogs. Proc. Natl. Acad. Sci. U.S.A. 75, 468-471.

Kouki, T., Kishitake, M., Okamoto, M., Oosuka, I., Takebe, M., and Yamanouchi, K. (2003). Effects of neonatal treatment with phytoestrogens, genistein and daidzein, on sex difference in female rat brain function: estrous cycle and lordosis. Horm. Behav. 44, 140-145.

Kuchera, L. K. (1971). Postcoital contraception with diethylstilbestrol. JAMA $218,562$.

Kudwa, A. E., Michopoulos, V., Gatewood, J. D., and Rissman, E. F. (2006). Roles of estrogen receptors alpha and beta in differentiation of mouse sexual behavior. Neuroscience 138, 921-928.

Kuhnle, G. G., Dell'Aquila, C., Aspinall, S. M., Runswick, S. A., Mulligan, A. A., and Bingham, S. A. (2008). Phytoestrogen content of beverages, nuts, seeds, and oils. J. Agric. Food Chem. 56, 7311-7315.

Kuiper, G. G., Lemmen, J. G., Carlsson, B. Corton, J. C., Safe, S. H., van der Saag, P. T., van der Burg, B., and Gustafsson, J. A. (1998). Interaction of estrogenic chemicals and phytoestrogens with estrogen receptor beta. Endocrinology 139, 4252-4263.

Kurzer, M. S., and Xu, X. (1997). Dietary phytoestrogens. Annu. Rev. Nutr. 17, 353-381.

Lapcik, O., Hill, M., Hampl, R., Wahala, K., and Adlercreutz, H. (1998). Identification of isoflavonoids in beer. Steroids 63, 14-20

Li, S. F., Hansman, R., Newbold, R., Davis, B., McLachlan, J. A., and Barrett, J.C. (2003). Neonatal diethylstilbestrol exposure induces persistent elevation of c-fos expression and hypomethylation in its exon-4 in mouse uterus. Mol. Carcinog. 38, 78-84.

Li, S. F., Washburn, K. A., Moore, R., Uno, T., Teng, C., Newbold, R. R., McLachlan, J. A., and Negishi, M. (1997). Developmental exposure to diethylstilbestrol elicits demethylation of estrogen-responsive lactoferrin gene in mouse uterus. Cancer Res. 57, 4356-4359.

Lisk, R. D. (1969). Progesterone: biphasic effects on the lordosis response in adult or neonatally gonadectomized rats. Neuroendocrinology 5, 149-160.

Lutz, W. K., Gaylor, D. W., Conolly, R. B. and Lutz, R. W. (2005). Nonlinearity and thresholds in dose-response relationships for carcinogenicity due to sampling variation, logarithmic dose scaling, or small differences in individual susceptibility. Toxicol. Appl. Pharmacol. 207(Suppl. 2), 565-569.

Mably, T.A., Moore, R.W., Goy, R. W., and Peterson, R. E. (1992). In utero and lactational exposure of male rats to 2,3,7,8-tetrachlorodibenzo-p-dioxin. 2. Effects on sexual behavior and the regulation of lutenizing hormone secretion in adulthood. Toxicol. Appl. Pharmacol. 114, 108-117.

Maffini, M. V., Rubin, B. S. Sonnenschein, C., and Soto, A. M. (2006). Endocrine disruptors and reproductive health: The case of bisphenol-A. Mol. Cell. Endocrinol. 254-255, 179-186.

Markey, C. M., Coombs, M. A., Sonnenschein, C., and Soto, A. M. (2003). Mammalian development in a changing environment: exposure to endocrine disruptors reveals the developmental plasticity of steroid-hormone target organs. Evol. Dev. 5, 67-75.

Markey, C. M., Luque, E. H., Munoz De Toro, M., Sonnenschein, C., and Soto, A. M. (2001). In utero exposure to bisphenol A alters the development and tissue organization of the mouse mammary gland. Biol. Reprod. 65, 1215-1223.

Markman, S., Leitner, S., Catchpole, C., Barnsley, S., Muller, C. T., Pascoe, D., and Buchanan, K. L. (2008). Pollutants increase song complexity and the volume of the brain area HVC in a songbird. PLOS ONE 3, e1674.

Marler, P. (2005). Ethology and the origins of behavioral endocrinology. Horm. Behav. 47, 493-502.

Matsushima, A., Kakuta, Y., Teramoto, T., Koshiba, T., Liu, X., Okada, H., Tokunaga, T., Kawabata, S., Kimura, M., and Shimohigashi, Y. (2007). Structural evidence for endocrine disruptor bisphenol A binding to human nuclear receptor ERR gamma. J. Biochem. 142, 517-524.

Mazur, W., and Adlercreutz, H. (2000). Overview of naturally occurring endocrine-active substances in the human diet in relation to human health. Nutrition 16, 654-658.

McLachlan, J. A., Newbold, R. R., Shah, H. C., Hogan, M. D., and Dixon, R. L. (1982). Reduced fertility in female mice exposed transplacentally to diethylstilbestrol (DES). Fertil. Steril. 38, 364-371.

Melnick, R., Lucier, G., Wolfe, M., Hall, R., Stancel, G., Prins, G., Gallo, M., Reuhl, K., Ho, S. M., Brown, T., Moore, J., Leakey, J., Haseman, J., and Kohn, M. (2002). Summary of the National Toxicology Program's report 
of the endocrine disruptors low-dose peer review. Environ. Health Perspect. 110, 427-431.

Metzler, M. (1981). The metabolism of diethylstilbestrol. CRC Crit. Rev. Biochem. 10, 171-212.

Milligan, S. R., Khan, O., and Nash, M. (1998). Competitive binding of xenobiotic oestrogens to rat alphafetoprotein and to sex steroid binding proteins in human and rainbow trout (Oncorhynchus mykiss) plasma. Gen. Comp. Endocrinol. 112, 89-95.

Milnes,M.R.,Bermudez,D.S.,Bryan, T. A., Gunderson, M. P., and Guillette, L. J.Jr. (2005).Altered neonatal development and endocrine function in Alligator mississippiensis associated with a contaminated environment. Biol. Reprod. 73, 1004-1010.

Muhlhauser, A., Susiarjo, M., Rubio, C., Griswold, J., Gorence, G., Hassold, T., and Hunt, P. A. (2009). Bisphenol A effects on the growing mouse oocyte are influenced by diet. Biol. Reprod. 80, 1066-1071.

Mylchreest, E., Sar, M., Cattley, R. C., and Foster, P. M. (1999). Disruption of androgen-regulated male reproductive development by di( $n$-butyl) phthalate during late gestation in rats is different from flutamide. Toxicol. Appl. Pharmacol. 156, 81-95.

Navarro, V.M., Fernandez-Fernandez, R., Castellano, J. M., Roa, J., Mayen, A., Barreiro, M. L., Gaytan, F., Aguilar, E., Pinilla, L., Dieguez, C., and TenaSempere, M. (2004). Advanced vaginal opening and precocious activation of the reproductive axis by KiSS-1 peptide, the endogenous ligand of GPR54. J. Physiol. 561, 379-386.

Newbold, R. (2006). Adverse effects of the model environmental estrogen diethylstilbestrol are transmitted to subsequent generations. Endocrinology 147(Suppl. 6), 11-17.

Newbold, R. R. (2008). Prenatal exposure to diethylstilbestrol (DES). Fertil. Steril. 89(Suppl. 2), e55-e56.

Newbold, R. R., Hanson, R. B., Jefferson, W. N., Bullock, B. C., Haseman, J., and McLachlan, J. A. (1998). Increased tumors but uncompromised fertility in the female descendants of mice exposed developmentally to diethylstilbestrol. Carcinogenesis 19, 1655-1663.

Newbold, R. R., Hanson, R. B., Jefferson, W. N., Bullock, B. C., Haseman, J., and McLachlan, J. A. (2000). Proliferative lesions and reproductive tract tumors in male descendants of mice exposed developmentally to diethylstilbestrol. Carcinogenesis 21, 1355-1363.

Newbold, R. R., and McLachlan, J. A. (1982). Vaginal adenosis and adeno- carcinoma in mice exposed prenatally or neonatally to diethylstilbestrol. Cancer Res. 42, 2003-2011.

Nyboe Andersen, A., and Erb, K. (2006). Register data on Assisted Reproductive Technology (ART) in Europe including a detailed description of ART in Denmark. Int. J. Androl. 29, 12-16.

Okura,A.,Arakawa, H., Oka,H., Yoshinari, T., and Monden, Y. (1988). Effect of genistein on topoisomerase activity and on the growth of [Val 12] Ha-rastransformed NIH 3T3 cells. Biochem. Biophys. Res. Commun. 157, 183-189.

Palmer,J.R., Wise, L.A., Robboy,S. J., TitusErnstoff, L., Noller, K. L., Herbst, A. L., Troisi, R., and Hoover, R. N. (2005). Hypospadias in sons of women exposed to diethylstilbestrol in utero. Epidemiology 16, 583-586.

Palmlund, I. (1996). Exposure to a xenoestrogen before birth: the diethylstilbestrol experience. J. Psychosom. Obstet. Gynaecol. 17, 71-84.

Palmlund, I., Apfel, R., Buitendijk, S., Cabau, A., and Forsberg, J. G. (1993). Effects of diethylstilbestrol (DES) medication during pregnancy: report from a symposium at the 10th international congress of ISPOG. J. Psychosom. Obstet. Gynaecol. 14, 71-89.

Pant, N., Shukla, M., Kumar Patel, D., Shukla, Y., Mathur, N., Kumar Gupta, Y., and Saxena, D. K. (2008). Correlation of phthalate exposures with semen quality. Toxicol. Appl. Pharmacol. 231, 112-116.

Parent, A. S., Teilmann, G., Juul, A., Skakkebaek, N. E., Toppari, J., and Bourguignon, J. P. (2003). The timing of normal puberty and the age limits of sexual precocity: variations around the world, secular trends, and changes after migration. Endocr. Rev. 24, 668-693.

Partsch, C. J., and Sippell, W. G. (2001). Pathogenesis and epidemiology of precocious puberty. Effects of exogenous oestrogens. Hum. Reprod. Update 7, 292-302.

Patchev, A. V., Gotz, F., and Rohde, W. (2004). Differential role of estrogen receptor isoforms in sex-specific brain organization. FASEB J. 18, 1568-1570.

Patisaul, H. B., Adewale, H. B., and Mickens, J. A. (2009a). Neonatal agonism of ERalpha masculinizes serotonergic (5-HT) projections to the female rat ventromedial nucleus of the hypothalamus (VMN) but does not impair lordosis. Behav. Brain Res. 196, 317-322.

Patisaul, H. B., Fortino, A. E., and Polston, E. K. (2006). Neonatal genistein or bisphenol-A exposure alters sexual differentiation of the AVPV. Neurotoxicol. Teratol. 28, 111-118.
Patisaul, H. B., Fortino, A. E., and Polston, E. K. (2007). Differential disruption of nuclear volume and neuronal phenotype in the preoptic area by neonatal exposure to genistein and bisphenol-A. Neurotoxicology 28, $1-12$.

Patisaul, H. B., Todd, K. L., Mickens, J. A. and Adewale, H. B. (2009b). Impact of neonatal exposure to the ER $\alpha$ agonist PPT, bisphenol-a or phytoestrogens on hypothalamic kisspeptin fiber density in male and female rats. Neurotoxicology 30, 350-357.

Peeters, P. H., Keinan-Boker, L., van der Schouw, Y. T., and Grobbee, D. E. (2003). Phytoestrogens and breast cancer risk. Review of the epidemiological evidence. Breast Cancer Res. Treat. 77, 171-183.

Penalvo, J. L., Adlercreutz, H., Uehara, M. Ristimaki,A., and Watanabe, S. (2008). Lignan content of selected foods from Japan. J. Agric. Food Chem. 56, 401-409.

Pfaff, D. (1999). Drive. Cambridge, MA, MIT Press.

Pfaff, D. W., and Sakuma, Y. (1979) Facilitation of the lordosis reflex of female rats from the ventromedial nucleus of the hypothalamus. J. Physiol. 288, 189-202.

Piontek, M., Hangels, K. J., Porschen, R. and Strohmeyer, G. (1993). Antiproliferative effect of tyrosine kinase inhibitors in epidermal growth factor-stimulated growth of human gastric cancer cells. Anticancer Res. 13, 2119-2123.

Polston, E. K., Gu, G., and Simerly, R. B. (2004). Neurons in the principal nucleus of the bed nuclei of the stria terminalis provide a sexually dimorphic GABAergic input to the anteroventral periventricular nucleus of the hypothalamus. Neuroscience 123, 793-803.

Polston, E. K., and Simerly, R. B. (2006) Ontogeny of the projections from the anteroventral periventricular nucleus of the hypothalamus in the female rat. J. Comp. Neurol. 495, 122-132.

Proos, L.A., Hofvander, Y., and Tuvemo, T. (1991). Menarcheal age and growth pattern of Indian girls adopted in Sweden. I. Menarcheal age. Acta Paediatr. Scand. 80, 852-858.

Recchia, A. G., Vivacqua, A., Gabriele, S. Carpino, A., Fasanella, G., Rago, V., Bonofiglio, D., and Maggiolini, M. (2004). Xenoestrogens and the induction of proliferative effects in breast cancer cells via direct activation of oestrogen receptor alpha. Food Addit. Contam. 21, 134-144.

Reinli, K., and Block, G. (1996). Phytoestrogen content of foods - a compendium of literature values. Nutr. Cancer 26, 123-148.
Roa, J., Vigo, E., Castellano, J. M., Navarro, V. M., FernandezFernandez, R., Casanueva, F. F., Dieguez, C., Aguilar, E., Pinilla, L., and Tena-Sempere, M. (2006). Hypothalamic expression of KiSS-1 system and gonadotropin-releasing effects of kisspeptin in different reproductive states of the female Rat. Endocrinology 147, 2864-2878.

Robboy, S. J., Szyfelbein, W. M., Goellner, J. R., Kaufman, R. H., Taft, P. D., Richard, R. M., Gaffey, T. A., Prat, J., Virata, R., Hatab, P. A., McGorray, S. P., Noller, K. L., Townsend, D., Labarthe, D., and Barnes, A. B. (1981). Dysplasia and cytologic findings in 4,589 young women enrolled in diethylstilbestroladenosis (DESAD) project. Am. J. Obset. Gynecol. 140, 579-586.

Robboy, S. J., Young, R. H., Welch, W. R., Truslow, G. Y., Prat, J., Herbst, A. L., and Scully, R. E. (1984). Atypical vaginal adenosis and cervical ectropion. Association with clear cell adenocarcinoma in diethylstilbestrol-exposed offspring. Cancer 54, 869-875.

Rogan, W. J., and Chen, A. (2005). Health risks and benefits of bis(4-chlorophenyl)-1,1,1-trichloroethane (DDT). Lancet 366, 763-773.

Rubin, B. S., Lenkowski, J. R., Schaeberle, C. M., Vandenberg, L. N., Ronsheim, P. M., and Soto, A. M. (2006). Evidence of altered brain sexual differentiation in mice exposed perinatally to low, environmentally relevant levels of bisphenol A. Endocrinology 147, 3681-3691.

Rubin,M.M.(2007). Antenatal exposure to DES: lessons learned...future concerns. Obstet. Gynecol. Surv. 62, 548-555.

Ruden, D. M., Xiao, L., Garfinkel, M. D. and Lu, X. (2005). Hsp90 and environmental impacts on epigenetic states: a model for the trans-generational effects of diethylstibesterol on uterine development and cancer. Endocrinology 14, R149-R155.

Sadler, B. R., Cho, S. J., Ishaq, K. S., Chae, K., and Korach, K. S. (1998). Three-dimensional quantitative structure-activity relationship study of nonsteroidal estrogen receptor ligands using the comparative molecular field analysis/cross-validated r2-guided region selection approach. J. Med. Chem. 41, 2261-2267.

Salama, J., Chakraborty, T. R., Ng, L., and Gore, A. C. (2003). Effects of polychlorinated biphenyls on estrogen receptor-beta expression in the anteroventral periventricular nucleus. Environ. Health Perspect. 111, 1278-1282.

Schiestl, R. H., Aubrecht, J., Yap, W. Y., Kandikonda, S., and Sidhom, S. 
(1997). Polychlorinated biphenyls and 2,3,7,8-tetrachlorodibenzo-p-dioxin induce intrachromosomal recombination in vitro and in vivo. Cancer Res. $57,4378-4383$.

Schoental, R. (1983). Precocious sexual development in Puerto Rico and oestrogenic mycotoxins (zearalenone). Lancet 1, 537.

SEER (2003). Cancer Statistics Review, 1975-2000. Bethesda, MD, National Cancer Institute. Available at: http:// seer.cancer.gov/csr/1975_2000.

Semenza, J. C., Tolbert, P.E., Rubin, C. H., Guillette, L. J. Jr., and Jackson, R. J. (1997). Reproductive toxins and alligator abnormalities at Lake Apopka, Florida. Environ. Health Perspect. 105, 1030-1032.

Setchell, K. D. (2001). Soy isoflavones benefits and risks from nature's selective estrogen receptor modulators (SERMs). J. Am. Coll. Nutr. 20(Suppl. 5), 354S-362S; discussion 381S-383S.

Setchell, K. D., Brown, N. M., Desai, P., Zimmer-Nechemias, L., Wolfe, B. E., Brashear, W. T., Kirschner, A. S., Cassidy, A., and Heubi, J. E. (2001). Bioavailability of pure isoflavones in healthy humans and analysis of commercial soy isoflavone supplements. J. Nutr. 131(Suppl. 4), 1362S-1375S.

Setchell, K. D., Gosselin, S. J., Welsh, M. B., Johnston, J. O., Balistreri, W. F., Kramer, L. W., Dresser, B. L., and Tarr, M. J. (1987). Dietary estrogens - a probable cause of infertility and liver disease in captive cheetahs. Gastroenterology 93, 225-233.

Setchell, K. D., Zimmer-Nechemias, L., Cai, J., and Heubi, J. E. (1998). Isoflavone content of infant formulas and the metabolic fate of these phytoestrogens in early life. Am. J. Clin. Nutr. 68, 1453S.

Setchell, K. D. R., and Welsh, M. B. (1987). High-performance liquid chromatographic analysis of phytoestrogens in soy protein preparations with ultraviolet electrochemical and thermospray mass spectrometric detection. J. Chromatogr. A 386, 315-323.

Setchell, K. D. R., Zimmer-Nechemias, L., Cai, J., and Heubi, J. E. (1997). Exposure of infants to phyto-oestrogens from soy-based infant formula. Lancet 350, 23-27.

Sharpe, R. M. (2003). The 'oestrogen hypothesis' - where do we stand now? Int. J. Androl. 26, 2-15.

Sheehan, D. M. (2006). No-threshold dose-response curves for nongenotoxic chemicals: findings and applications for risk assessment. Environ. Res. 100, 93-99.

Shughrue, P. L., Lane, M. V., and Merchenthaler, I. (1997). Comparative distribution of estrogen receptor $\alpha$ and $\beta$ mRNA in the rat central nervous system. J. Comp. Neurol. 388, 507-525.

Simerly, R. B. (1998). Organization and regulation of sexually dimorphic neuroendocrine pathways. Behav. Brain Res. 92, 195-203.

Simerly, R. B. (2002). Wired for reproduction: organization and development of sexually dimorphic circuits in the mammalian forebrain. Annu. Rev. Neurosci. 25, 507-536.

Simerly, R. B., Chang, C., Muramatsu, M., and Swanson, L. W. (1990). Distribution of androgen and estrogen receptor mRNA-containing cells in the rat brain: an in situ hybridization study. J. Comp. Neurol. 294, 76-95.

Skakkebaek, N. E., Jorgensen, N., Main, K. M., Rajpert-De Meyts, E., Leffers, H., Andersson, A. M., Juul, A., Carlsen, E., Mortensen, G. K., Jensen, T. K., and Toppari, J. (2006). Is human fecundity declining? Int. J. Androl. 29, 2-11.

Skakkebaek, N. E., Rajpert-De Meyts, E., and Main, K. M. (2001). Testicular dysgenesis syndrome: an increasingly common developmental disorder with environmental aspects. Hum. Reprod. 16, 972-978.

Smith, J. T., Clifton, D. K., and Steiner, R. A. (2006a). Regulation of the neuroendocrine reproductive axis by kisspeptinGPR54 signaling. Reproduction 131, 623-630.

Smith, J. T., Popa, S. M., Clifton, D. K., Hoffman, G. E., and Steiner, R. A. (2006b). Kissl neurons in the forebrain as central processors for generating the preovulatory luteinizing hormone surge. J. Neurosci. 26, 6687-6694.

Smith, O.W. (1948). Diethylstilbestrol in the prevention and treatment of complications of pregnancy. Am. J. Obset. Gynecol. 56, 821-834.

Sodersten, P. (1978). Effects of antioestrogen treatment of neonatal male rats on lordosis behaviour and mounting behaviour in the adult. J. Endocrinol. 76, 241-249.

Steinberg, R. M., Walker, D. M., Juenger, T. E., Woller, M. J., and Gore, A. C. (2008). Effects of perinatal polychlorinated biphenyls on adult female rat reproduction: development, reproductive physiology, and second generational effects. Biol. Reprod. 78, 1091-1101.

Stenchever, M. A., Williamson, R. A., Leonard, J., Karp, L. E., Ley, B., Shy, K., and Smith, D. (1981). Possible relationship between in utero diethylstilbestrol exposure and male fertility. Am. J. Obset. Gynecol. 140, 186-193.

Strom, B. L., Schinnar, R., Ziegler, E. E., Barnhart, K. T., Sammel, M. D.,
Macones, G. A., Stallings, V. A., Drulis, J. M., Nelson, S. E., and Hanson, S. A. (2001). Exposure to soy-based formula in infancy and endocrinological and reproductive outcomes in young adulthood. JAMA 286, 807-814.

Sun, Y., Irie, M., Kishikawa, N., Wada, M. Kuroda, N., and Nakashima, K. (2004). Determination of bisphenol A in human breast milk by HPLC with column-switching and fluorescence detection. Biomed. Chromatogr. 18, 501-507.

Susiarjo, M., Hassold, T. J., Freeman, E., and Hunt, P. A. (2007). Bisphenol A exposure in utero disrupts early oogenesis in the mouse. PLoS Genet. 3, e5.

Swaab, D. F., and Hofman, M. A. (1984) Sexual differentiation of the human brain. A historical perspective. Prog. Brain Res. 61, 361-374.

Swan, S.H., Brazil, C., Drobnis, E.Z., Liu, F. Kruse, R. L., Hatch, M., Redmon, J. B. Wang, C., and Overstreet, J.W. (2003). Geographic differences in semen quality of fertile U.S. males. Environ. Health Perspect. 111, 414-420.

Swan, S. H., Elkin, E. P., and Fenster, L. (2000). The question of declining sperm density revisited: an analysis of 101 studies published 19341996. Environ. Health Perspect. 108, 961-966.

Swan,S.H.,Main,K.M.,Liu,F.,Stewart, S. L., Kruse, R. L., Calafat, A. M., Mao, C. S., Redmon, J. B., Ternand, C. L., Sullivan, S., and Teague, J. L. (2005). Decrease in anogenital distance among male infants with prenatal phthalate exposure. Environ. Health Perspect. 113, 1056-1061.

Tang, W.Y., Newbold, R., Mardilovich, K., Jefferson, W., Cheng, R. Y., Medvedovic, M., and Ho, S.M. (2008) Persistent hypomethylation in the promoter of nucleosomal binding protein 1 (Nsbp1) correlates with overexpression of Nsbp1 in mouse uteri neonatally exposed to diethylstilbestrol or genistein. Endocrinology 149, 5922-5931.

Tena-Sempere, M. M. (2006). KiSS-1 and reproduction: focus on its role in the metabolic regulation of fertility. Neuroendocrinology 83, 275-281.

Thomas, P., and Dong, J. (2006). Binding and activation of the seven-transmembrane estrogen receptor GPR30 by environmental estrogens: a potential novel mechanism of endocrine disruption. J. Steroid Biochem. Mol. Biol. 102, 175-179.

Thompson, L. U., Boucher, B. A., Liu, Z. Cotterchio, M., and Kreiger, N. (2006). Phytoestrogen content of foods consumed in Canada, including isofla- vones, lignans, and coumestan. Nutr. Cancer 54, 184-201.

Thompson, L. U., Robb, P., Serraino, M., and Cheung, F. (1991). Mammalian lignan production from various foods. Nutr. Cancer 16, 43-52.

Todaka, E., Sakurai, K., Fukata, H., Miyagawa, H., Uzuki, M., Omori, M., Osada, H., Ikezuki, Y., Tsutsumi, O., Iguchi, T., and Mori, C. (2005). Fetal exposure to phytoestrogens - the difference in phytoestrogen status between mother and fetus. Environ. Res. 99, 195-203.

Toppari, J., Larsen, J. C., Christiansen, P., Giwercman, A., Grandjean, P., Guillette, L. J., Jr., Jégou, B., Jensen, T. K., Jouannet, P., Keiding, N., Leffers, H., McLachlan, J. A., Meyer, O., Müller, J., Rajpert-De Meyts, E., Scheike, T., Sharpe, R., Sumpter, J., and Skakkebaek, N. E. (1996). Male reproductive health and environmental xenoestrogens. Environ. Health Perspect. 104(Suppl. 4), 741-803.

Tsutsumi, O. (2005). Assessment of human contamination of estrogenic endocrine-disrupting chemicals and their risk for human reproduction. J. Steroid Biochem. Mol. Biol. 93, 325-330.

Vandenberg, L. N., Hauser, R., Marcus, M., Olea, N., and Welshons, W. V. (2007). Human exposure to bisphenol A (BPA). Reprod. Toxicol. 24, 139-177.

Vandenberg, L. N., Maffini, M. V., Sonnenschein, C., Rubin, B. S., and Soto, A. M. (2009). Bisphenol-A and the great divide: a review of controversies in the field of endocrine disruption. Endocr. Rev. 30, 75-95.

Vandenberg, L. N., Wadia, P. R., Schaeberle, C. M., Rubin, B. S., Sonnenschein, C., and Soto, A. M. (2006). The mammary gland response to estradiol: monotonic at the cellular level, non-monotonic at the tissue-level of organization? J. Steroid Biochem. Mol. Biol. 101, 263-274.

Venners, S.A., Korrick, S., Xu, X., Chen, C., Guang, W., Huang, A., Altshul, L., Perry, M., Fu, L., and Wang, X. (2005). Preconception serum DDT and pregnancy loss: a prospective study using a biomarker of pregnancy. Am. J. Epidemiol. 162, 709-716.

Vessey, M. P., Fairweather, D. V., NormanSmith, B., and Buckley, J. (1983). A randomized double-blind controlled trial of the value of stilboestrol therapy in pregnancy: long-term follow-up of mothers and their offspring. $\mathrm{Br}$. J. Obstet. Gynaecol. 90, 1007-1017.

Vivacqua, A., Recchia, A. G., Fasanella, G., Gabriele, S., Carpino, A., Rago, V., Di Gioia, M. L., Leggio, A., Bonofiglio, D., 
Liguori, A., and Maggiolini, M. (2003). The food contaminants bisphenol A and 4-nonylphenol act as agonists for estrogen receptor alpha in MCF7 breast cancer cells. Endocr. J. 22, 275-284.

vom Saal, F. S., Akingbemi, B. T., Belcher, S. M., Birnbaum, L.S., Crain, D. A., Eriksen, M., Farabollini, F., Guillette, L. J., Hauser, R., Heindel, J. J., Ho, S. M., Hunt, P. A., Iguchi, T., Jobling, S., Kanno, J., Keri, R. A., Knudsen, K. E.,Laufer,H.,LeBlanc, G. A., Marcus, M., McLachlan, J. A., Myers, J. P., Nadal, A., Newbold, R. R., Olea, N., Prins, G. S., Richter, C. A., Rubin, B. S., Sonnenschein, C., Soto, A. M., Talsness, C. E., Vandenbergh, J. G., Vandenberg, L. N., Walser-Kuntz, D. R., Watson, C. S., Welshons, W. V., Wetherill, Y., and Zoeller, R. T. (2007). Chapel Hill bisphenol A expert panel consensus statement: integration of mechanisms, effects in animals and potential to impact human health at current levels of exposure. Reprod. Toxicol. 24, 131-138.

vom Saal, F. S., and Moyer, C. L. (1985). Prenatal effects on reproductive capacity during aging in female mice. Biol. Reprod. 32, 1116-1126.

Vrieling, H., Duhl, D. M., Millar, S. E., Miller, K. A., and Barsh, G. S. (1994). Differences in dorsal and ventral pigmentation result from regional expression of the mouse agouti gene. Proc. Natl. Acad. Sci. U.S.A. 91, 5667-5671.

Wadia, P. R., Vandenberg, L. N., Schaeberle, C. M., Rubin, B. S., Sonnenschein, C., and Soto, A. M.
(2007). Perinatal bisphenol A exposure increases estrogen sensitivity of the mammary gland in diverse mouse strains. Environ. Health Perspect. 115, 592-598.

Walker, B. E., and Haven, M. I. (1997). Intensity of multigenerational carcinogenesis from diethylstilbestrol in mice. Carcinogenesis 18, 791-793.

Waterland, R. A., and Jirtle, R. L. (2003). Transposable elements: targets for early nutritional effects on epigenetic gene regulation. Mol. Cell. Biol. 23, 5293-5300.

Watson, C. S., Bulayeva, N. N., Wozniak, A. L., and Alyea, R.A. (2007). Xenoestrogens are potent activators of nongenomic estrogenic responses. Steroids 72, 124-134.

Weuve, J., Sanchez, B. N., Calafat, A. M., Schettler, T., Green, R. A., Hu, H., and Hauser, R. (2006). Exposure to phthalates in neonatal intensive care unit infants: urinary concentrations of monoesters and oxidative metabolites. Environ. Health Perspect. 114, 1424-1431.

Whalen, R. E., and Nadler, R. D. (1963). Suppression of the development of female mating behavior by estrogen administered in infancy. Science 141, 273-274.

Whales, R. E., Gladue, B. A., and Olsen, K. L. (1986). Lordotic behavior in male rats: genetic and hormonal regulation of sexual differentiation. Horm. Behav. 20, 73-82.

Wilcox, A. J., Baird, D. D., Weinberg, C. R., Hornsby, P.P., and Herbst, A. L. (1995).
Fertility in men exposed prenatally to diethylstilbestrol. N. Engl. J. Med. 332, 1411-1416.

Wirth, J. J., Rossano, M. G., Potter, R., Puscheck, E., Daly, D. C., Paneth, N., Krawetz, S. A., Protas, B. M., and Diamond, M. P. (2008). A pilot study associating urinary concentrations of phthalate metabolites and semen quality. Syst. Biol. Reprod. Med. 54, 143-154.

Wisniewski, A. B., Klein, S. L., Lakshmanan, Y., and Gearhart, J. P. (2003). Exposure to genistein during gestation and lactation demasculinizes the reproductive system in rats. J. Urol. 169, 1582-1586.

Wolf, C. J., LeBlanc, G. A., Ostby, J. S., and Gray, L. E. Jr. (2000). Characterization of the period of sensitivity of fetal male sexual development to vinclozolin. Toxicol. Sci. 55, 152-161.

Wolff, G. L., Kodell, R. L., Moore, S. R., and Cooney, C. A. (1998). Maternal epigenetics and methyl supplements affect agouti gene expression in Avy/a mice. FASEB J. 12, 949-957.

Xu, J., Osuga, Y., Yano, T., Morita, Y., Tang, X., Fujiwara, T., Takai, Y., Matsumi, H., Koga, K., Taketani, Y., and Tsutsumi, O. (2002). Bisphenol A induces apoptosis and G2-to-M arrest of ovarian granulosa cells. Biochem. Biophys. Res. Comm. 292, 456-462.

Yamanouchi, K., and Aria, Y. (1976). Heterotypical sexual behavior in male rats: individual difference in lordosis respones. Endocrinol. Jpn. 23, 179-182.
You, L., Casanova, M., Bartolucci, E. J., Fryczynski, M. W., Dorman, D. C., Everitt, J. I., Gaido, K. W., Ross, S. M., and Heck, H. A. (2002). Combined effects of dietary phytoestrogen and synthetic endocrine-active compound on reproductive development in Sprague-Dawley rats: genistein and methoxychlor. Toxicol. Sci. 66, 91-104.

Young,W.C., Goy, R.W., and Phoinis, C. H. (1964). Hormones and sexual behavior. Science 143, 212-218.

Zervos, C., and Rodricks, J. V. (1982). FDA's ban of DES in meat production. Am. Stat. 36, 278-283.

Conflict of Interest Statement: The authors declare that the research was conducted in the absence of any commercial or financial relationships that could be construed as a potential conflict of interest.

Received: 01 May 2009; paper pending published: 18 May 2009; accepted: 10 June 2009; published online: 29 June 2009. Citation: Patisaul HB and Adewale $H B$ (2009) Long-term effects of environmental endocrine disruptors on reproductive physiology and behavior. Front. Behav. Neurosci. (2009) 3:10. doi:10.3389/neuro.08.010.2009

Copyright (c) 2009 Patisaul and Adewale. This is an open-access article subject to an exclusive license agreement between the authors and the Frontiers Research Foundation, which permits unrestricted use, distribution, and reproduction in any medium, provided the original authors and source are credited. 